Ambulatory Assessment of Physiological Arousal, Emotion, and Alcohol Use

A Dissertation
Presented to
The Faculty of the Graduate School
At the University of Missouri
In Partial Fulfillment
Of the Requirements for the Degree
Doctor of Philosophy
BACHEL L. TOMKO
Buth
Dimothy Trull, Dissertation Supervisor
Dr. 2015


(C) Copyright by Rachel Tomko 2015

All Rights Reserved 
The undersigned, appointed by the dean of the Graduate School, have examined the dissertation entitled

\section{AMBULATORY ASSESSMENT OF PHYSIOLOGICAL AROUSAL, EMOTION, AND ALCOHOL USE}

Presented by Rachel L. Tomko, a candidate for the degree of Doctor of Philosophy, and hereby certify that, in their opinion, it is worthy of acceptance.

Timothy J. Trull, Ph.D.

Denis M. McCarthy, Ph.D.

Phillip K. Wood, Ph.D.

Paul D. Bolls, Ph.D. 


\section{ACKNOWLEDGEMENTS}

I am indebted to many individuals for their support and feedback on this dissertation. First, I would like to thank my advisor, Dr. Tim Trull, for his support and guidance throughout this project. Additionally, I would like to thank Drs. Paul Bolls, Don Fowles, Steve Hackley, Denis McCarthy, Scott Saults, Kenneth Sher, and Phil Wood for their helpful feedback and expertise. This project would not have been possible without the assistance of numerous undergraduate research assistants who helped with participant recruitment and data collection. Specifically, I would like to acknowledge the hard work of Jenna Cousins-Pahde, Alaina Harris, Kayla Kilpatrick, Aaron Templemire, Amy Veith, and Ali Ward. I am grateful to many others for their support and their direct contributions to this project. I am especially thankful to Anthony Almond, Whitney Brown, Ryan Carpenter, Russell Clayton, Kristin Mclaughlin, Emily Scheiderer, and Cindy Tomko. Lastly, I would like to acknowledge funding for this project from the National Institute on Alcohol Abuse and Alcoholism Grants P60AA011998 (Heath) and F31 AA022031 (Tomko). 


\section{TABLE OF CONTENTS}

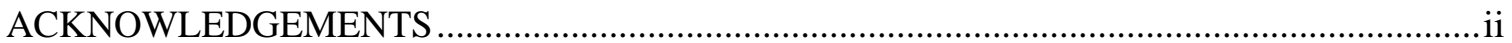

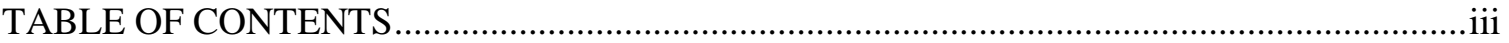

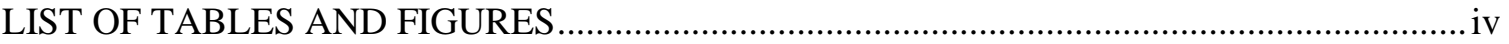

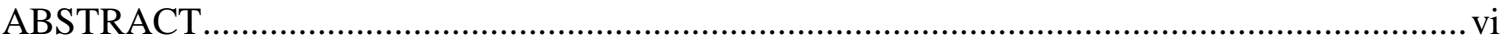

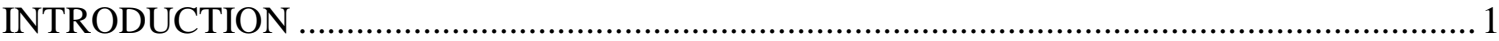

Alcohol's Effect on Stress and Negative Emotions

Electrodermal Activity (EDA)

Ambulatory Measures of Electrodermal Activity

Current Study

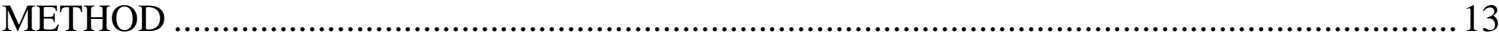

Physiological Assessment

Laboratory Stimuli

Self-Report

Laboratory Procedure

Ambulatory Procedure

Analytic Strategy

RESULTS

Correspondence Between Traditional and Ambulatory EDA Recording Devices

Real-World Affect, EDA, and Alcohol Use

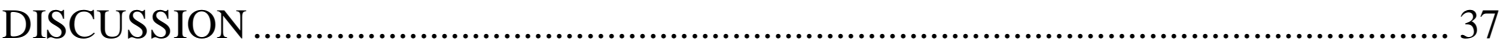

Agreement Between Measures in Laboratory

Ambulatory Assessment of Alcohol Use Outcomes

Implications for Development of Alcohol Use Disorders

Limitations and Future Directions

Summary and Conclusions

APPENDIX

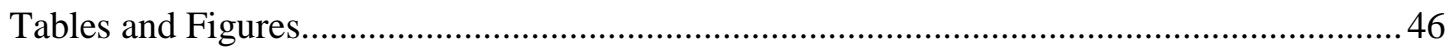

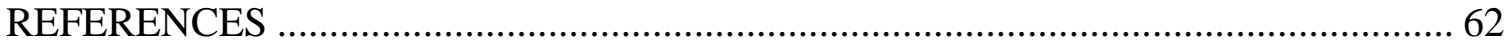

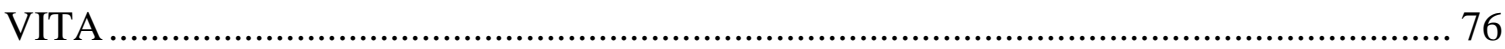




\section{LIST OF TABLES AND FIGURES}

1. Table 1 46

Demographic and Psychiatric Characteristics of Sample

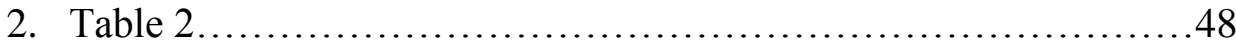

Means, Standard Deviations, and Correlations Between $Q$ Sensor and Biopac in Laboratory

3. Table 3a.

Correlations Between Daily Ambulatory Skin Conductance Variables

4. Table $3 b$

Correlations Between Daily Ambulatory Skin Conductance Variables and Ambulatory Affect Variables

5. Table 4

Correlations Between Ambulatory Affect, Ambulatory Skin Conductance, and Retrospective Self-Report

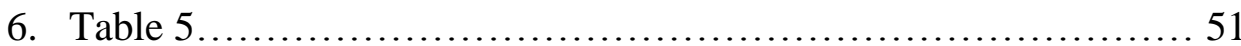

Zero-Inflated Poisson (ZIP) Multilevel Model: Negative Affect, Positive Affect, and Electrodermal Activity as Predictors of Number of Drinks Per Day

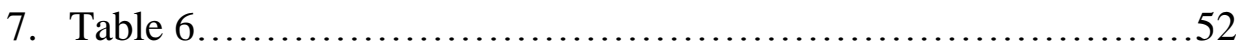

Zero-Inflated Poisson Multilevel Model: Fear, Positive Affect, and Electrodermal Activity as Predictors of Number of Drinks Per Day

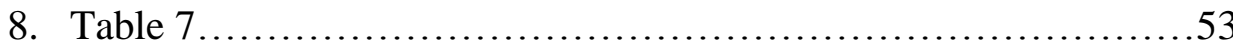

Zero-Inflated Poisson Multilevel Model: Hostility, Positive Affect, and Electrodermal Activity as Predictors of Number of Drinks Per Day

9. Table 8

Zero-Inflated Poisson Multilevel Model: Sadness, Positive Affect, and Electrodermal Activity as Predictors of Number of Drinks Per Day

10. Table 9

Negative Affect, Positive Affect, and Electrodermal Activity as

Predictors of Maximum Estimated Blood Alcohol Concentration 


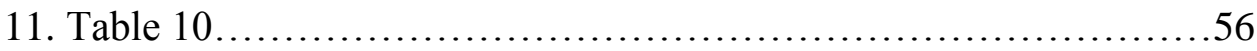

Fear, Positive Affect, and Electrodermal Activity as Predictors of Maximum Estimated Blood Alcohol Concentration

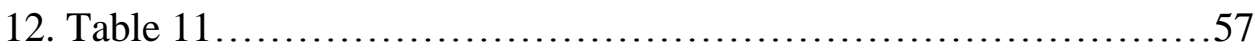

Hostility, Positive Affect, and Electrodermal Activity as Predictors of Maximum Estimated Blood Alcohol Concentration

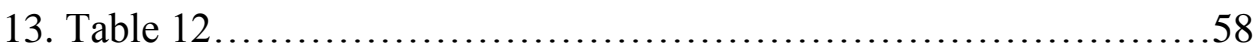

Sadness, Positive Affect, and Electrodermal Activity as Predictors of Maximum Estimated Blood Alcohol Concentration

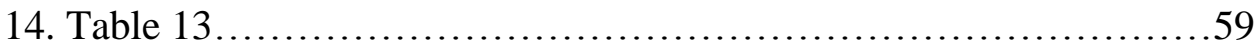

Trait Affective Instability, Negative Affect, Positive Affect, and Electrodermal Activity as Predictors of Maximum Estimated Blood Alcohol Concentration

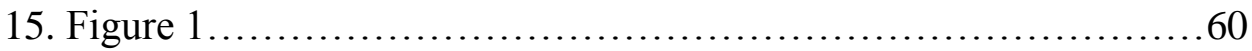

Drink Reports by Day of Week

16. Figure 2. .61

Drink Reports by Time of Day 


\begin{abstract}
The literature examining whether negative affect leads to drinking has produced mixed results (Greeley \& Oei, 1999; Sher \& Grekin, 2007). General difficulty in emotion regulation may be a risk factor for problematic alcohol use; however, Sher and Grekin (2007) suggest that emotion dysregulation must be severe enough to interfere with the use of more adaptive emotion regulation strategies. Thus, the current project enlisted participants $(\mathrm{n}=43)$ oversampled for affective instability/emotion dysregulation, arguably making them at higher risk for negative affect-driven alcohol consumption. The goals of this study were to 1) validate an ambulatory device for measuring electrodermal activity and to 2) examine the relations between emotion, electrodermal activity, and alcohol use in real-time. Multiple self-reports of emotion, alcohol use, and behavior were obtained from participants each day over the course of one week using electronic diaries. Further, physiological arousal was assessed continuously during waking hours via electrodermal activity (EDA). The results suggested that ambulatory measurement of EDA is feasible, and agreement between ambulatory measures and traditional laboratory measures was good for number of skin conductance responses per minute. Skin conductance level was less consistent across measures. With regard to ambulatory findings, high negative affect and high arousal states during the day were generally related to decreased likelihood of same-day drinking and decreased estimated blood alcohol concentration, while positive affect was related to increased likelihood of drinking. Hostility and number of skin conductance responses interacted, such that low hostility and low arousal was related to
\end{abstract}


greater amounts of alcohol consumed. In sum, negative affect and arousal were related to alcohol use in real-time, but effects were small and both were generally protective against alcohol consumption at the day-level. This study helps to clarify the role of arousal in affect-related drinking, while also adding to accumulating evidence that suggests negative affect-related drinking may not be an immediate coping response. Positiveaffect drinking may be most relevant in early stages of alcohol use, even in an emotionally dysregulated sample. 


\section{INTRODUCTION}

Affect regulation has long been theorized to be a psychological motivator for alcohol consumption. Over sixty years ago, Wikler (1948) suggested that individuals use drugs to avoid or escape aversive states. Conger (1956) described the tension reduction hypothesis, which posits that alcohol consumption reduces stress, making alcohol use reinforcing. Thus, in future episodes of stress, people may be more likely to consume alcohol. To date, many researchers still argue the importance of negative reinforcement as a motivator for alcohol use (Cooper, Frone, Russell, \& Mudar, 1995; Baker, Piper, McCarthy, Majeskie, \& Fiore, 2004). Providing further evidence for negative reinforcement models, alcohol use disorders are highly comorbid with depressive disorders, anxiety disorders, and the combination of both (Kessler et al., 1997). Additionally, Feldstein Ewing, Filbey, Chandler, and Hutchison (2010) have demonstrated that brain regions associated with emotion and reward are more greatly activated in response to alcohol cues among individuals with symptoms of depression or anxiety.

The importance of coping motives in the prediction of drinking has also been demonstrated (Cooper et al., 1995). Individuals who are motivated to drink to reduce negative affect or stress may show increased rates of drinking as compared to those who do not share these motivations to drink. Further, individuals' expectation that alcohol may reduce aversive states may motivate consumption, regardless of how strongly alcohol produces the desired effect (Armeli, Conner, Cullum, \& Tennen, 2010; Treloar, Piasecki, McCarthy, Sher, \& Heath, in press).

Despite general acceptance of negative reinforcement theories and evidence showing strong relationships between emotion dysregulation and alcohol use at the individual-level, negative affect is not consistently associated with alcohol consumption when assessed in real- 
time. Ambulatory assessment (defined here as ongoing data collection in participants' natural environments) provides an ecologically valid measure of drinking and drinking contexts. Ambulatory assessment of alcohol use has produced mixed results regarding the association between negative affect and subsequent drinking (Armeli, Todd, \& Mohr, 2005; Armeli, Dehart, Tennen, Todd, \& Affleck, 2007; Mohr et al., 2001; Todd, Armeli, \& Tennen, 2009; Cooney et al., 2007; Hussong, 2007). Armeli and colleagues (2010) further note that even among individuals who report high coping motives, drinking does not often occur near in time to a stressor. This is consistent with Volpicelli's (1987) extension of Conger's tension reduction hypothesis. Volpicelli suggests that "alcohol drinking does not increase in anticipation of, or during tense situations but does increase following these events" (p. 381). Specifically, Volpicelli suggests that as a result of an uncontrollable stressful event, opiate receptor activity is increased, which is followed by endorphin depletion after the removal of the stressor. Alcohol increases opiate receptor activity; thus, after repeated self-administrations, individuals may learn to compensate for endorphin depletion by consuming alcohol. As such, it is likely that negativeaffect alcohol relations are evident at the day-level, week-level, or month-level. However, it is less likely that an individual will respond to negative affect by consuming alcohol relatively immediately. Therefore, the goal of the current study is to examine day-level associations between negative affect and drinking. However, even at the day-level, findings have been mixed.

There are a number of other potential explanations as to why ambulatory assessment studies fail to find strong negative affect-alcohol relations. First, many studies do not account for level of arousal and rely solely on self-report of affect valence. The anxiolytic properties of 
alcohol are likely most reinforcing for high arousal, negative affective states. Thus, the current study will take into consideration physiological arousal.

Second, most of the existing studies have used college students, community samples, and other non-treatment seeking samples. Emotion dysregulation may be a risk factor for problematic alcohol use; however, Sher and Grekin (2007) suggest that emotion dysregulation must be sufficiently severe to lead to the use of such maladaptive emotion regulation strategies. Thus, given the lack of consensus in the literature, it is necessary to use a high-risk sample characterized by difficulties with emotion regulation. In the current study, one specific form of emotion dysregulation, affective instability, was examined. Affective instability was defined as “marked reactivity of mood (e.g., intense episodic dysphoria, irritability, or anxiety usually lasting a few hours and only rarely more than a few days)" (American Psychiatric Association, 2013, p. 663), consistent with the DSM-5 criterion for borderline personality disorder (BPD). Though affective instability is often studied in the context of a BPD diagnosis, it is a transdiagnostic construct and can manifest in other disorders such as posttraumatic stress disorder, atypical depression, rapid cycling bipolar disorders, and frontal or temporal brain diseases (Koenigsberg, 2010). Koenigsberg (2010) describes affective instability as a multifaceted construct, which includes rapid rise in emotional intensity, excessive reactivity to external stimuli, and quick transitions between different emotional states. Affective instability and disorders characterized by affective instability are strong predictors of problematic alcohol use (Kupka et al., 2005; Pietrzak, Goldstein, Southwick, \& Grant, 2011; Tomko, Trull, Wood, \& Sher, 2014). In sum, the purpose of the current study is to identify whether negative affect is 
related to increased alcohol use when physiological arousal is considered, particularly among individuals oversampled for trait affective instability.

\section{Alcohol's Effect on Stress and Negative Emotions}

Sher (1987) described two ways in which alcohol can lessen negative reactions to stressors. First, stress response to an event is reduced when one is under the influence of alcohol [stress response dampening (SRD); see Sher, 1987; Greeley \& Oei, 1999; Sher, Bartholow, Peuser, Erickson, \& Wood, 2007]. Importantly, Sher and colleagues (2007) demonstrated that alcohol reduces physiological arousal, as measured by electrodermal activity (EDA), during a stressful task. Secondly, stress may be reduced by subsequent alcohol use administered after the occurrence of the stressor. This is known as stress response recovery (SRR; Noel, Lisman, Schare, \& Lederer, 1981; Sher, 1987), and it has received less experimental research attention in comparison. The current study examines this latter mechanism using real-time EDA and selfreported emotion as indicators of affective states. Critically, most existing research has focused on SRD effects rather than negative subjective states (or hyperarousal) that precede, and may contribute to, alcohol use. Studies have shown that drinkers are most likely to experience stress reductions when alcohol consumption precedes the stressor (Sayette, 1993a; Sayette et al., 2001).

As mentioned above, in addition to modulating emotion, alcohol consumption has been shown to impact autonomic responses (e.g., Sher, 1987; Greeley \& Oei, 1999; Udo et al., 2009). Fowles (1980) theorized that approach behaviors, or reward-driven behaviors, are related to autonomic hyper-reactivity as indicated by increased heart rate. Avoidance of potential punishment is related to autonomic hyper-reactivity as measured by electrodermal activity (Fowles, 1980). Given these are distinct risk factors for alcohol use, it is possible that different 
affect-alcohol relations may be observed depending on the psychophysiological index. Specifically, increased electrodermal activity in the context of negative affect may be associated with a higher likelihood of drinking, while increased heart rate coupled with high positive affect may be a separate risk factor. The current study focuses on heightened negative affect and electrodermal activity as predictors of alcohol use; however, positive affect will also be measured to determine whether there is specificity of valence of affect above and beyond electrodermal activity alone.

Importantly, research suggests that people also drink when experiencing positive affect (e.g., Swendsen et al., 2000; Mohr et al., 2001; Todd, Armeli, Tennen, Carney, \& Affleck, 2003) and have reported enhancement motives for drinking (Cooper et al., 1995). Furthermore, both enhancement and coping motives can occur within the same individual. To further support this, recent electronic diary studies examining the dynamics of self-reported emotion and alcohol use in real-time have found that both positive affect (PA) and negative affect (NA) are predictive of drinking (e.g., Mohr et al., 2001; Hussong, Hicks, Levy, \& Curran, 2001).

Both PA and NA can be associated with physiological hyperarousal (Dawson, Schell, \& Filion, 2007). Additionally, research demonstrates a relation between physiological hyperarousal and drinking (see Carter \& Tiffany, 1999). Autonomic nervous system functioning is associated with familial risk for alcohol dependence (Finn, Earleywine, \& Pihl, 1992), and poor modulation of EDA is associated with substance use disorders (Taylor, 2004). Hyperarousal, indexed by EDA, does not characterize all phases of an alcohol use episode, however. As blood alcohol concentration (BAC) rises to its peak (ascending limb), physiological arousal increases, specifically EDA (Jones, Parsons, \& Rundell, 1976; Sher, 1987). Depending on dosage 
(Donohue, Curtin, Patrick, \& Lang, 2007) and limb effects, alcohol can also lead to decreased EDA (Sher, 1987; Sher et al., 2007). Similarly, studies show that heart rate (HR) initially increases when one consumes alcohol (Sayette, 1993b; Sher et al., 2007). Increased HR is related to activation of the endogenous opioid system and, therefore, the reward system (Conrod, Peterson, \& Pihl, 2001; Sher et al., 2007). Given that EDA is more specific to anxiolytic effects or the avoidance of negative states (Beauchaine, 2001, Sher et al., 2007), it is the primary focus of the current study. Studies assessing ambulatory EDA and its relation to alcohol use are lacking, as are studies that examine EDA preceding alcohol use, as a predictor of use. Electrodermal Activity (EDA)

Physiological arousal, specifically as indexed by EDA, increases when one is exposed to novel or personally significant stimuli, is physically active, is under psychological stress, or is engaging in a task that requires full attention (Dawson et al., 2007; Boucsein et al., 2012). EDA is a broad term for sweat gland activity underneath the skin, which reflects activation of the sympathetic branch of the Autonomic Nervous System (ANS). Humans have three kinds of sweat glands in the body: apocrine, apoeccrine, and eccrine (see Dawson et al., 2007 for a review). Eccrine sweat glands are of particular interest in the study of psychological phenomena because they are involved in thermoregulation and emotional arousal. Eccrine sweat glands are most densely located on palmar and plantar surfaces (i.e., hands and feet; Dawson et al., 2007), thus, it is recommended that EDA is measured from these locations of the body (Boucsein et al., 2012).

Traditionally, EDA is measured in a laboratory setting and specific recommendations regarding how laboratory-based measures of EDA should be obtained have been published by 
experts in the field (Boucsein et al., 2012). EDA recordings in laboratory-based settings afford the investigator a high degree of experimental control. Investigators have control over stimulus presentation, timing of stimulus presentation, room temperature, and other variables that may impact EDA. Further, the environment and stimuli can be standardized across participants. Additionally, any deviations from standard protocol (e.g., participant movement, extraneous noises) are observed and recorded. Because of the high degree of experimental control, the investigator can make conclusions about how various experimental manipulations (e.g., anger mood induction) affect EDA.

One major limitation of laboratory based studies, however, is the potential lack of generalizability to real-world settings. Participants' behavior as studied in the laboratory may systematically differ from their behavior when they self-select into interpersonal interactions and environments (Buss, 1987). For example, participants may feel that there are certain expectations about their behavior in a laboratory setting, which may increase socially desirable responding and/or anxiety (Orne, 1962; Foster \& Cone, 1995). Often investigators are interested in realworld behaviors which are not fully captured in the laboratory setting. A number of ambulatory assessment techniques have been developed in order to circumvent this problem, including ambulatory measures of EDA. Ambulatory assessment methods, also known as ecological momentary assessment (EMA) or experience sampling, are designed to monitor individuals in their natural environments and to maintain ecological validity of assessment (Fahrenberg, 1996). Ambulatory Measures of Electrodermal Activity

Investigators have attempted to measure ambulatory EDA as early as the 1980s (Simpson \& Turpin, 1983; Turpin, Shine, \& Lader, 1983). Simpson and Turpin (1983) noted that one 
major difficulty in ambulatory EDA monitoring is designing a device that is small, portable, and maintains accurate EDA measurement. Several investigators have examined ambulatory EDA since this time, using a number of different recording devices. Most of these studies used a relatively brief monitoring period ( 24 hours or less) and some maintain a relatively controlled, ambulatory environment. For example, Wilhelm and Roth (1998) monitored participants' ambulatory EDA (among other psychophysiological measures) during an airplane flight. They were interested in whether ambulatory psychophysiological indicators could distinguish between individuals with flight phobia and those without flight phobia. Wilhelm and Roth (1998) were able to measure EDA before, during, and after the flight, for a total duration of approximately five to six hours. They found that individuals with flight phobia showed more frequent skin conductance fluctuations, but there were no differences in skin conductance levels across groups. The recording device was placed in a waist pack worn by the participant and the electrodes were placed on the palmar surface of the left hand.

Hoehn-Saric and colleagues (2004) monitored EDA over a similar length of time in individuals with panic disorder, generalized anxiety disorder, and non-anxious controls. Participants wore a device that attached to the shoulders and waist, and EDA electrodes were placed on fingers on the non-dominant hand. Participants wore the device on four separate occasions for eight hours each time, but due to technical errors, only six hours of each recording period was analyzed. Hoehn-Saric and colleagues (2004) observed decreased skin conductance variance in the anxious groups as compared to the non-anxious controls.

More recently, ambulatory EDA has been used to detect falls in elderly individuals (Nocua, Noury, Gehin, Dittmar, \& McAdams, 2009), examine associations between autonomic 
activity and epileptic seizures (Poh, Loddenkemper et al., 2012), examine psychophysiological precursors to panic attacks (Meuret et al., 2011), provide biofeedback to adolescent mothers (Rajan et al., 2012), examine associations between EDA and sleep in high versus low worriers (Weise, Ong, Tesler, Kim, \& Roth, 2013), examine stress response during students' thesis defenses (Elfering \& Grebner, 2011), and to detect hot flashes in women (e.g., Carpenter et al., 2005; Pachman et al., 2013). Thus, ambulatory measurement of EDA can have important clinical implications.

Although ambulatory EDA assessment has important potential clinical benefits, such as warning of an epileptic seizure (Poh et al., 2012), the construct validity of these measures has not been extensively tested. Importantly, the more that ambulatory methods deviate from traditional laboratory assessment, the more critical it is to establish construct validity. The creators of one specific device for measurement of ambulatory EDA, the Q Sensor, opted to place the recording electrodes on the wrist. They selected the wrist as a less intrusive alternative recording location because placement of electrodes on the palm or distal phalanges for extended periods of time can impede participants' daily routines (Poh, Swenson, \& Picard, 2010). Expert guidelines for EDA research suggest that the wrist, a recording site location often used in modern ambulatory EDA, is not preferred, as the sweat gland activity of the wrist is thought to reflect thermoregulation rather than psychological or emotional responding (Boucsein et al., 2012). However, Poh, Swenson, and Picard (2010) provided preliminary evidence suggesting that the Q Sensor produces similar patterns of data as compared to the "gold standard," which in their study was EDA measured from the medial phalanges. In a sample of 26 participants, they observed correlations of 0.93 or higher between the Q Sensor recordings and their comparison "gold 
standard" method (recorded via Flexcomp Infiniti, Thought Technologies, Ltd.) for baseline, a cognitive task, physical task, and an emotional task. Importantly, Poh, Swenson, and Picard (2010) did not use conductive gel for either the Q Sensor recording or "gold standard" comparison. This reduced methodological variance in their study; however, conductive gel is commonly used in laboratory EDA studies (Boucsein et al., 2012).

An independent set of researchers have compared traditional palmar measurements of EDA to 15 other sites on the body (van Dooren, de Vries, \& Janssen, 2012). Their results suggest that measurements from the wrist were significantly correlated with palmar EDA readings $(\mathrm{r}=0.57)$. Compared to the other sites examined in their study, the wrist measurements fell into an “intermediate" category, suggesting that wrist recordings were moderately related to palmar EDA readings, but that the foot, thighbone, and shoulders all produced closer results to palmar recordings. Importantly, van Dooren and colleagues (2012) did not use the Q Sensor and used the same electrodes at all recording sites. The Q Sensor differs in other critical ways from traditional laboratory electrode recordings, leaving additional room for variation between the two measures. For example, the Q Sensor uses $\mathrm{Ag} / \mathrm{AgCl}$ electrodes without any conductive gel, while most laboratory studies use disposable $\mathrm{Ag} / \mathrm{AgCl}$ electrodes that come pre-filled with electrode gel.

Thus, even if ambulatory EDA devices can produce reliable recordings, it is possible that they are not capturing the same construct that is typically measured in the laboratory. To better understand what is being measured by ambulatory EDA devices, it is necessary to directly compare readings from traditional laboratory-measured EDA recorded from recommended recording sites, such as on the palm or on the distal phalanges. This comparison has important 
implications for how researchers might interpret EDA recordings from ambulatory devices, like the Q Sensor. Additionally, the direct comparison will provide more information about where ambulatory EDA fits in the nomological network of laboratory-measured EDA.

\section{Current Study}

The first goal of the current study was to determine the extent to which electrodermal recordings from the Q Sensor correspond with traditional electrodermal recordings on the palmar surface using a Biopac recording system. In order to achieve this goal, correlations between the two recording sites are computed. van Dooren and colleagues (2012) found a correlation of 0.57 between skin conductance measured at the distal phalanges and skin conductance measured at the central wrist location. (However, van Dooren et al. did not examine the thenar and hypothenar sites on the palm, as was used in the current study.) In their study, both measurements were recorded using the same recording system and the same electrode type (Ag/AgCl gel electrodes). Given that the recording system, electrode location, and electrode type varies in the current study, it was hypothesized that a 0.57 correlation between the Q Sensor and traditional recording via the palm is the upper limit of congruence for the current study. Because both devices are intended to measure the same constructs, a medium to large correlation was expected. Thus, it was hypothesized that the observed correlations between Q Sensor and traditional measurements would fall between 0.4 and 0.57 in a controlled laboratory setting.

The second goal of the current study was addressed using ambulatory assessment. Specifically, a real-time measure of EDA was used in conjunction with real-time self-report of affect and alcohol use via electronic diary to test whether high arousal, negative affect states result in increased likelihood of drinking and/or greater amount of alcohol consumed. The 
current study adds to the existing literature on alcohol, emotion, and physiological arousal by uniquely 1) examining states of hyperarousal antecedent to alcohol use in natural settings, 2) estimating participants' BAC curves based on weight, gender, and reported alcohol use, 3) controlling for movement when assessing ambulatory EDA, and 4) studying a population oversampled for affective instability. It was hypothesized that increased physiological arousal would interact with negative mood states to predict drinking and that this effect would be greatest for those high in affective instability. Specifically, it was hypothesized that when negative affect and physiological arousal were both high, alcohol use and amount of alcohol consumed would be greater. 


\section{METHOD}

Participants $(n=43)$ were recruited from a list of individuals who participated in other, previous studies on emotion dysregulation and/or alcohol use. Participants were re-contacted and told about the procedures for the current study. At the time of their initial participation, individuals who were interested in additional studies provided consent to be contacted in the future. The current sample consisted of participants who consented to be contacted for additional studies, were able to be reached for follow-up, and agreed to participate in the current study. In order to be eligible for the current study, participants must have been administered the Structured Interview for DSM-IV Personality (SIDP-IV; Pfohl, Blum, \& Zimmerman, 1994) by lab staff during their prior participation. All participants were also administered a structured diagnostic interview assessing for mood, anxiety, and substance use disorders. Depending on the study from which a participant was recruited, participants were administered either the Structured Clinical Interview for DSM-IV Axis I Disorders (SCID-I; First, Spitzer, Gibbon, \& Williams, 1995) or the Mini-International Neuropsychiatric Interview (MINI; Lecrubier et al., 1997). For the current project, participants met the general eligibility criteria if they: 1) were between the ages of 18 and 45,2 ) if female, were not pregnant or planning to become pregnant, 3 ) had no history of head trauma that has resulted in sustained impairment in mood, attention, or concentration, 4) had consumed alcohol at least 4 times in the past month, 5) did not endorse withdrawal symptoms when not using alcohol, 6) did not endorse multiple unsuccessful efforts to cut down on alcohol use, and 7) were not currently seeking treatment or interested in seeking treatment for drinking related problems. Participants who met criteria for borderline personality disorder (BPD) with affective instability (BPD + AI; $n=14)$, affective instability in the absence of a full 
BPD diagnosis (AI only; $n=10)$, and controls without BPD or AI $(n=19)$ were sampled for the purposes of the current study.

The average age of participants was 26.67 years ( $\mathrm{SD}=7.67$; Range 19-46). Demographic and psychiatric information for the current sample is shown in Table 1.

It is important to note that participants were not excluded if they were taking psychiatric medications, including medications with anticholinergic properties. Medications with anticholinergic properties can reduce electrodermal activity (Schlenker et al., 1995), and many commonly prescribed psychiatric medications have anticholinergic properties. Because a nonmedicated sample would not be representative of individuals with borderline personality disorder (see Tomko, Trull, et al., 2014) or affective instability more broadly, individuals on medications were not excluded from the current study. Rather, a list of medications was obtained from each participant. The probable anticholinergic burden of each medication was determined by referencing Carnahan and colleagues (2006). Carnahan and colleagues assigned a score from 0 to 3 for each medication, with 0 indicating that the medication did not have anticholinergic properties and 3 indicating severe anticholinergic effects. For analytic purposes, a binary variable was created to indicate "moderate to severe anticholinergic medications." Participants who had any medication with a rating of 2 or above on the anticholinergic burden scale were coded "1" on this variable.

Four participants were taking a medication that was not included in the Carnahan et al. (2006) study. In two of these cases, information was obtained from Chew et al. (2008). In the other two cases, the anticholinergic properties of the medication could not be identified. Both participants who were prescribed a medication with unknown anticholinergic properties were 
also taking a medication that was known to have mild anticholinergic properties. Thus, these participants were categorized as having "some anticholinergic medications" in relevant analyses, and were excluded from analyses that required a categorization of "moderate to severe" anticholinergic properties.

Of the 43 participants, $58.1 \%(n=25)$ were taking a medication for psychiatric purposes and $69.8 \%(n=30)$ were taking a medication for any condition. Of the 30 who were taking any medication, $66.7 \%(n=20)$ were prescribed a medication with at least mild anticholinergic properties (1 or greater on Anticholinergic Burden Scale) and 28.6\% ( $\mathrm{n}=8$ out of 28 ) were prescribed a medication with moderate to severe anticholinergic properties ( 2 or greater on Anticholinergic Burden Scale).

Physiological Assessment

Eligible participants completed two laboratory sessions and a week of ambulatory monitoring. Only data from the first laboratory session is used in the current analyses for purpose of comparing two forms of EDA assessment.

Traditional Recording. EDA was assessed using the MP150 Data Acquisition System with the Galvanic Skin Response (GSR) module (BioPac Systems, Inc.). For EDA measurement, $\mathrm{Ag} / \mathrm{AgCl}$ electrodes, which are standard for EDA research (Lykken \& Venables, 1971; Boucsein et al., 2012), were placed on the thenar and hypothenar eminences of the palm. A sodium chloride $(\mathrm{NaCl})$ electrode gel was used to reduce humidity under the electrodes. The GSR module uses a direct constant voltage of $0.5 \mathrm{~V}$.

$Q$ Sensor. Electrodermal Activity (EDA) was measured using a sensor worn on the inner side of the left wrist (Q Sensor, Affectiva). The Q Sensor is designed to measure arousal, 
temperature, and 3-axis movement (Poh et al., 2010). EDA can be measured by passing a small current through two electrodes on the surface of the skin (Dawson et al., 2007). The Q Sensor applies a direct current through $\mathrm{Ag} / \mathrm{AgCl}$ disc electrodes, which is a standard for EDA research (Lykken \& Venables, 1971; Boucsein et al., 2012). This measures tonic skin conductance, and more informatively, changes in skin conductance across different states of emotion, attention, and arousal. A sampling frequency of $32 \mathrm{~Hz}$ was used and an average voltage of $0.47 \mathrm{~V}$ is applied. See Poh et al. (2010) for additional details. Data from the Q Sensor device were timeand date-stamped.

\section{Laboratory Stimuli}

Arousal Induction. A blast of cool air was applied to the bottom of the participants' bare right foot after the baseline. Participants were aware that they would feel a blast of air, but were unaware of when the air blast would occur. This produced a large electrodermal response from participants.

Emotion Induction. Participants watched a series of short films to elicit specific emotions (Gross \& Levenson, 1995; Rottenberg, Ray, \& Gross, 2007). These films were chosen to elicit reactions of sadness ("The Champ"- 2'51", "Return to Me"-3'36"), anger ("My Bodyguard"- 4'6", "Cry Freedom"- 2'36"), fear ("The Shining"-1'22", "Silence of the Lambs"-3'29"), amusement ("Cosby"- 2'01"; "When Harry Met Sally"- 2'35"), and neutrality ("Sticks"- 3'26", "Denali"$\left.5^{\prime} 02^{\prime \prime}\right)$. One film from each emotion category was played at each session so that each participant viewed five films of different emotional valence in Session 1 and the five remaining films in Session 2. The order of the films was randomized across participant and session. 
Positive and Negative Affect Scale-Laboratory Administration (PANAS; Watson, Clark, \& Tellegen, 1988; Watson \& Clark, 1994)). Affect was assessed using items from the Positive and Negative Affect Schedule-Extended version (PANAS-X; Watson \& Clark, 1999). Items were presented one at a time to participants on a monitor. A total of 42 items were administered from the following scales: negative affect, positive affect, fear, sadness, hostility, joviality, fatigue, and attentive. For each affect item, respondents were asked to rate the extent to which they felt the particular affective state on a five point Likert scale (1=very slightly or not at all to 5=extremely). Participants rated their affect after each film clip. Self-Report

Demographics. A demographics form was administered that asks for sex, age, marital status, religion, education, household income, number of children, ethnicity, race, previous hospitalizations, current medications, health and relationship information.

Depression Anxiety Stress Scales (DASS; Lovibond \& Lovibond, 1995). The DASS is a 42-item self-report measure designed to assess depression, anxiety, and tension/stress in the past week. Participants respond to items using a 4-point Likert scale ranging from 0 ("Did not apply to me at all") to 3 ("Applied to me very much, or most of the time"). In previous samples, internal consistency was excellent (Lovibond \& Lovibond, 1995; Brown et al., 1997).

Difficulties in Emotion Regulation Scale (DERS; Gratz \& Roemer, 2004). The DERS is a 40-item questionnaire used to assess facets of emotion regulation including nonacceptance of emotions, difficulties engaging in goal-directed behavior, impulse control difficulties, lack of emotional awareness, limited emotion regulation strategies, and lack of emotional clarity. Internal consistency was 0.80 or greater for each of the six sub-scales (Gratz \& Roemer, 2004). 
For the purpose of the current study, the sum of all subscale scores is used as an indicator of general emotion dysregulation.

Drinking Motives Questionnaire (DMQ; Cooper et al., 1995). The DMQ is a 20-item questionnaire used to assess enhancement, coping, conformity, and social motives for alcohol use. Each item is rated on a 5-point scale ranging from 1 (almost never/never) to 5 (almost always/always). All subscales have an internal consistency above 0.80 .

Personality Assessment Inventory-Borderline Features Scale (PAI-BOR; Morey, 1991). The PAI-BOR is a 24-item self-report measure with 4 subscales each representing a key feature of BPD (e.g., affective instability). Each statement is rated on a 4-point scale ( $0=$ "false" to 3="very true"). The PAI-BOR has good internal consistency (0.91 in a clinical sample) and testretest reliability (0.86).

Positive and Negative Affect Schedule-Electronic Diary Administration (PANAS; Watson, Clark, \& Tellegen, 1988; Watson \& Clark, 1994). For ambulatory assessment, 31 items from the PANAS were administered at each assessment. In particular, two 10-item scales for PA and NA were administered, in addition to 11 additional items forming fear, sadness, and hostility subscales. The PANAS shows high internal consistency for both PA and NA scales, and good discriminant and convergent validity. At each time point, participants are asked to rate their mood "right now" on a 5-point scale ( $1=$ "not at all" to $5=$ "extremely"). Momentary affective composites were computed by taking the average of $10 \mathrm{NA}$ items at each time point (i.e., momentary negative affect) and 10 PA items at each time point (i.e., momentary positive affect). Daily NA was centered about each individual's own mean NA affect score across the entire study period (i.e., weekly average NA) as a measure of within-person variation. Additionally, daily NA 
was centered about the grand mean across all participants in the study, as a measure of betweenperson variation. The same procedure was followed for PA, fear, sadness, and hostility.

Ambulatory Self-Report Assessments. Self-report was collected via electronic diaries (Palm Tungsten, E2, Palm Computing Inc.) with software designed by Invivodata, Inc.

(Pittsburgh, PA). Specifically, five types of diary data were collected for the same 7 day period: 1) random reports (diary alarms at random times to assess mood, urges to drink, social context, and current behavior), 2) event-based reports (when the participant consumed an alcoholic drink, they initiated a report on the diary), 3) event follow-up reports (at set intervals following a reported drinking event, participants were asked follow-up questions regarding mood, craving, drinking behaviors, and consequences of drinking), 4) morning reports (every morning, the participant retrospectively reported on drinking the previous day and informed the diary that he/she is awake, which began the possibility of random prompts), and 5) bedtime reports (before going to sleep, the participant put the diary "to sleep" which terminated any subsequent event follow-up prompts). Electronic diary self-reports included items regarding alcohol consumption (i.e., report number of standard drinks) and mood states. Mood items are from the PANAS (described above). The primary outcome variables of interest included alcohol day (0 if no alcohol was consumed, 1 if alcohol was consumed), number of drinks per day, and maximum estimated blood alcohol concentration (eBAC) per drinking episode. Maximum eBAC was estimated using a formula by Matthews and Miller (1979) and Hustad and Carey (2005). This formula takes into account gender of the individual, weight of the individual, number of drinks consumed, duration of drinking episode, and assumes a rate of alcohol metabolism in a given hour to be $0.017 \mathrm{~g} / \mathrm{dl}$. Because participants were instructed to $\log$ a drink after they had 
consumed one standard drink, the duration of the drinking episode was calculated by subtracting the time between first reported drink and last reported drink. An additional 20 minutes was added to the beginning of each drinking episode as a rough estimate of the time it took to consume the first drink in the episode.

\section{Laboratory Procedure}

Participants were asked to refrain from consuming a meal or caffeine 2 hours prior to each laboratory visit. They were also asked to refrain from exercising or consuming drugs or alcohol within 24 hours of the laboratory visit. No formal biomarkers were obtained to confirm compliance with these requests. Once in the laboratory, participants were consented to study procedures. Participants were seated upright in a comfortable chair. The Q Sensor was placed on the participant's left wrist. Participants completed a packet of self-report questionnaires before baseline recording began in order to allow for acclimation to the laboratory setting. Following questionnaires, a resting baseline was obtained by having the participant sit quietly for 10 minutes while EDA was recorded. After the baseline period, the arousal induction described above occurred. Then, participants watched a series of films (one film clip for each emotion listed above, counter-balanced) on 32-inch monitor with the lights dimmed. Each film clip was preceded by brief instructions to stay alert and watch the film closely. After each film, participants reported their current emotional states using a computerized version of the PANAS. Finally, participants received instruction on the ambulatory phase of the study (Session 1 only). Participants were compensated with a $\$ 25$ gift card to Amazon or Walmart following the initial visit. 


\section{Ambulatory Procedure}

Participants carried the electronic diary during waking hours for approximately 7 consecutive full days. Participants also wore the Q Sensor device on their non-dominant hand during waking hours during the same time period, except in cases in which it could be damaged by water or overheated. Each night, participants were instructed to charge the Q Sensor. Finally, participants were asked to press the button on the Q Sensor once to indicate each time they were beginning to drink an alcoholic beverage. Participants returned their devices to the laboratory at the conclusion of the ambulatory period and were compensated with a $\$ 50$ gift card to Amazon or Walmart.

Analytic Strategy

Correspondence Between Traditional and Mobile EDA Recording Devices. To determine the correspondence between Q Sensor measured EDA and traditionally measured EDA, a number of indices were computed. First, the data were averaged to one data point per second. This resulted in the same number of data points from both the Q Sensor and Biopac. Second, artifacts were removed by computing the standard deviation in EDA for each person during the laboratory session. Any observation which was one standard deviation greater than the previous (lagged) observation was replaced with the value of the lagged observation, as this was considered to be an unusually steep rise in EDA likely resulting from an artifact. Third, epochs were created for each segment of the laboratory session. These epochs include one 1-minute baseline $^{1}$, five film clips, and one 30 -second interval following the arousal induction (i.e., blast

\footnotetext{
${ }^{1}$ Sixty (60) consecutive seconds relatively free of movement artifacts were selected at random from the last two minutes of a 10-minute baseline for each period. Previous research has used the end of the baseline period to compute change scores (Rubenking \& Lang, 2014).
} 
of air on foot), resulting in a total of seven epochs. For each epoch, the following indices were computed: mean skin conductance level (SCL), number of skin conductance responses per minute (SCRs-0.01/min) defined as an increase in SCL greater than 0.01 microSiemens $(\mu \mathrm{S})$, number of skin conductance responses per minute (SCRs-0.05/min), defined as an increase in SCL greater than $0.05 \mu \mathrm{S}$, average skin temperature, and average activity defined as the total distance moved during the epoch. Physical activity or movement was computed via the accelerometer on the Q Sensor. The Q Sensor provided values at each time point for distance moved on the x-axis, $\mathrm{y}$-axis, and $\mathrm{z}$-axis. Using the equation for distance derived from the Pythagorean Theorem, distance was computed by taking the square root of $\left(x^{2}+y^{2}+z^{2}\right)$. Finally, the amplitude of the air blast SCR was computed by subtracting the maximum EDA value in the 30-second interval following the air blast from the average SCL during the 1 minute baseline (baseline immediately preceded the air blast).

Correlations between Q Sensor and Biopac data were computed for SCL, SCR-0.01/min, and SCR-0.05/min for each epoch. In addition, the correlation between Q Sensor and Biopacmeasured SCR-amp for the air puff was computed.

Real-World Affect, EDA, and Alcohol Use. Ambulatory Q Sensor data was sampled at 32 Hz. Thus, due to the large number of observations over the course of the study, data were first reduced to one observation per second by taking the average of all observations per second. Then, the same process for identifying artifacts in the laboratory was applied to real-world data - any observation greater than one standard deviation above the observation one second prior was replaced with the previous observation. Although participants were asked to complete a 10-minute daily "rest period" to obtain a daily baseline, a number of challenges resulted in 
minimal usable day-to-day baseline data. First, there were no reminders via the electronic diary to complete these baseline periods and compliance was poor. Additionally, accidental button presses made it difficult to discern when the baseline period was completed. However, use of a daily baseline is not without limitation. Although there are day-to-day fluctuations in EDA, there are also diurnal fluctuations in EDA. Thus, adjusting an afternoon assessment based on a morning baseline reading may be misleading. Alternatively, Boucsein (2012) proposed using skin conductance responses per minute as a primary measure of interest, as it can account somewhat for the moving baseline. An increase of at least $0.05 \mu \mathrm{S}$ was used for all ambulatory analyses, as this threshold showed slightly higher correlations with affective variables, suggesting it may be a better indicator of arousal due to affective processes (see Table 3). In addition, a residualized index of each of the aforementioned measures was created. Variance due to physical activity was removed. Correlations between each of these ambulatory measures are provided in Table 3 as a reference.

Multilevel modeling (MLM) was used to analyze all ambulatory data. MLM is robust to missing data, differing numbers of observations across participants, and unequally spaced time intervals. MLM also allows for estimation of both within and between subject variance. Failure to account for within subject variance can result in an increased probability of Type I errors (Gibbons, Hedeker, \& DuToit, 2010). Two-level MLM was used to examine the association between affect, EDA, and drinking outcomes. Level 1 consisted of the daily assessments for each person, such as daily affect and EDA, and allowed for the estimation of within-individual variability. Level 2 represented individual-level variables, such as trait affective instability as measured by the PAI-BOR AI subscale. Zero-inflated multilevel models were conducted using 
SAS Proc NLMIXED with Laplace approximation when number of drinks was the outcome variable of interest. A zero-inflated Poisson mixed model was used to predict number of drinks consumed. The logistic part of the model represents an estimation of the likelihood that an observation is equal to zero, while the Poisson part represents an estimation of the number of drinks once zero-inflation is considered. Thus, positive predictors in the logistic part of the model are associated with abstinence, rather than alcohol consumption. While zero-inflated Poisson mixed models are advantageous in that the number of drinks consumed can be modeled with all observations (including observations equal to zero) included, there are some limitations to these models in the current sample. Specifically, zero-inflated Poisson models can be problematic with small sample sizes. Thus, separate logistic and Poisson multilevel models are also presented. The logistic model was computed using Proc GLIMMIX link function predicting the binary outcome of abstinence. The Poisson model was computed using Proc GLIMMIX predicting number of drinks when all zero observations are removed.

SAS Proc MIXED (Littell, Milliken, Stroup, \& Wolfinger, 1996) was used when maximum eBAC was the outcome of interest and these analyses were limited to drinking days. Variance was estimated using the Residual Maximum Likelihood (REML) method. REML produces less biased estimators for random parameters than Maximum Likelihood (ML) Estimation, especially with small sample sizes (Snijders \& Bosker, 1999). However, both estimation procedures are based on the ML principle. They differ in terms of standard error estimation and REML outperforms ML when there are a large number of fixed effects in the model. 
Missing Data. Data missing from self-report questionnaires was replaced with the mean of the other items for the individual from that particular sub-scale. Weight data was missing for one female participant. The mean weight of the other female participants ( $\mathrm{M}=155 \mathrm{lbs})$ was imputed for this individual for the purpose of estimating BAC.

With regard to laboratory data, technical difficulties resulted in invalid Biopac data and/or unreliable Q Sensor timestamp data for 13 participants, precluding comparisons between Biopac and Q Sensor data. Thus, lab analyses were limited to a sample size of 30.

With regard to ambulatory data, the first and last days of data collection were partial days for all participants, as participants began using the devices after their initial appointment time and up to when they returned devices to the laboratory. Data from partial days was not included for several reasons. First, since the primary predictor variables were affective and physiological states throughout the day prior to a drinking episode, incomplete data may bias the results for the day. Second, participants may show greater reactivity to the devices early in participation when the study protocol is novel. Removing data from the first half day allows participants to habituate to the study devices. Participants with four or more days of EMA data were included in the current analyses and all available data was used. Two participants did not provide this minimum and were dropped from all ambulatory analyses. The remaining 41 participants had an average of 7.02 completed full days $(\mathrm{SD}=0.94, \mathrm{Min}=4, \mathrm{Max}=10)$. In some instances, the monitoring period was extended if technical difficulties were experienced with one or more devices. Due to technical difficulties resulting in data loss, 5 additional participants did not have complete ambulatory EDA data, resulting in a remaining sample size of 36. Of the participants with complete ambulatory data, 2 participants did not report drinking during the study period. Since 
alcohol use was the outcome of interest, these participants were also removed from these analyses. Thus, ambulatory EMA and EDA analyses are limited to a sample size of 34 . 


\section{RESULTS}

\section{Correspondence Between Traditional and Ambulatory EDA Recording Devices}

First, as a manipulation check, it was determined whether EDA measures differed from the equivalent baseline EDA measure. For Biopac, all video conditions had significantly more SCRs per minute than baseline. The Q Sensor data was less consistent, as some epochs had significantly more SCRs per minute than baseline (anger, happy, neutral-0.05) and some had significantly fewer SCRs per minute than baseline (neutral-0.01, fear, sadness). However, as described below, baseline Q Sensor and Biopac measurements showed weak correspondence and Q sensor data should be used as a comparable measure with caution.

As shown in Table 2, on average, the Q Sensor produced higher SCLs than traditional laboratory measurement via Biopac. However, Biopac measurement produced more frequent SCRs. Thus, laboratory assessment appears to be more sensitive to change in level. It was hypothesized that the correlations between Q Sensor and traditional measurements would fall between 0.4 and 0.57 . For SCRs per minute (at both $0.01 \mu \mathrm{S}$ and $0.05 \mu \mathrm{S}$ cut-offs), this hypothesis was largely supported, except at baseline. In fact, there were instances where the correlation between Q Sensor and traditional laboratory measure exceeded 0.57. For example, Q Sensor and traditional laboratory measurement of SCRs per minute at a $0.01 \mu \mathrm{S}$ cut-off were highly correlated across video epochs $(r=0.60)$ and, in particular, for the sadness epoch $(r=0.64)$, happy epoch $(r=0.66)$, and neutral epoch $(r=0.60)$. The correlation also exceeded 0.57 for SCRs per minute at a $0.05 \mu \mathrm{S}$ cut-off for the happy epoch $(r=0.58)$. Of note, at baseline, there was no significant relationship between SCR measures. Further, Q Sensor and traditional laboratory assessment SCL values were significantly negatively correlated ( $r=-0.46)$ at baseline. This may 
suggest that the Q Sensor and Biopac measures show differential relationships with EDA over time. For instance, it is generally thought EDA increases over time with traditional measurement. It is possible that the Q Sensor shows the opposite pattern. Offering further support for this idea, Q Sensor SCL at baseline was $1.00(\mathrm{SD}=1.47)$, on average and during videos Q Sensor SCL averaged $0.27(\mathrm{SD}=1.05)$. Biopac measurements increased from $-0.01(\mathrm{SD}=0.05)$ at baseline to 0.02 (0.08) during video epochs, on average. It is important to note that participants wore the $\mathrm{Q}$ Sensor during pre-baseline questionnaires, prior to the Biopac electrodes being attached.

With few exceptions, correlations between Q Sensor and Biopac SCLs were smaller than the hypothesized size range, but generally significantly positively correlated. Change in SCL from baseline after the air blast correlated 0.37 between measures. SCL video correlations ranged from 0.12 (neutral epoch) to 0.42 (anger epoch).

Real-World Affect, EDA, and Alcohol Use

Compliance with Protocol. Participants were compliant with the protocol, as demonstrated by an $87.2 \%(\mathrm{SD}=13.9)$ average response rate to random prompts on the electronic diary. Participants in final EMA sample wore the Q Sensor 93.2\% ( $\mathrm{SD}=14.2)$ of study days. Self-reported Alcohol Use Via Electronic Diary. The 34 participants retained for ambulatory data analyses, reported an average of 8.3 drinks $(\mathrm{SD}=6.2$; Range $=2-34)$ per person across full days in the study period. The number of drinking days per participant was 2.8 , on average $(\mathrm{SD}=1.2$; Range $=1-5)$. The number of binge days per participant was 0.65 , on average ( $\mathrm{SD}=0.81$, Range $=0-3)$. There were 85 drinking episodes for which maximum eBAC was computed. The average number of drinks consumed per drinking day was $2.8(\mathrm{SD}=2.8$, Range $=1-24)$. The average maximum eBAC was $0.06(\mathrm{SD}=0.08$, Range $=0.01-0.69)$. One 
drinking episode resulted in an eBAC greater than 0.20 and this value was replaced with the value 0.20 for multilevel models, as this likely represents a formula estimation error at higher amounts of alcohol consumed. This individual reported 24 drinks in one drinking episode. The next highest eBAC was 0.18 and the next highest number of drinks reported was 8 within a single drinking episode. To minimize overdispersion and to meet the assumptions of the Poisson distribution, which assumes that the mean is equal to the variance, observations with more than 5 drinks were coded as 6 drinks. This resulted in a mean of 2.55 drinks per drinking episode $(\mathrm{SD}=1.58, \mathrm{Var}=2.50)$. Only two values were replaced using this method. Drinking episodes were slightly more prevalent on weekends, as shown in Figure 1. Only $8.3 \%$ of drinks reported fell between the hours of 5 AM and 4 PM. Thus, 5 AM-4 PM was considered "day" and affect from day time was used to predict later drinking.

\section{EDA and Daily Negative Affect as Predictors of Alcohol Use and Number of Drinks}

Consumed. Anticholinergic burden was correlated with affective instability on the PAI-AI subscale $(r=0.29, p<0.01)$ and anxiety as measured by the DASS $(r=0.27, p=0.01)$, but not correlated with skin conductance responses per minute centered around the individual $(r=-0.04$, $p=0.69)$ or group $(r=0.01, p=0.91)$ mean; thus, it is not entered as a covariate in this (or, any subsequent) multilevel model.

Main effects and interaction terms were entered as predictors. Specifically, mean daily NA (before 4 PM), PA (before 4 PM), and number of skin conductance responses per minute per day (before 4 PM) were entered into the model, with each variable centered on the individual's average on the respective variable across the entire study period (person centered). Additionally, mean daily NA (before 4 PM), PA (before 4 PM), and number of skin conductance responses per 
minute per day (before 4 PM) were also centered on the mean for all individuals in the study (grand mean centered). The model was estimated using random intercept only due to small sample size. Additionally, a binary variable for weekend (1) versus weekday (0) was modeled as a fixed effect and entered as a predictor. Fridays and Saturdays were considered weekend and all other days were considered weekday.

Additional covariates and interaction terms were included, but removed from the model if the p-value was greater than .25. The interaction between within-person (person centered) NA and SCR/min was included in the model, as was the interaction between within-person (person centered) PA and SCR/min. Both interaction terms had a p-value greater than 0.25 and were removed from the final model.

Daily NA, PA, and SCRs per minute were entered as predictors in a zero-inflated Poisson mixed model. Table 5 shows that PA (as centered about the mean across all participants) was significantly negatively related to abstaining from alcohol use that day $(\mathrm{b}=-0.91, p=0.04)$, but unrelated to number of drinks consumed $(b=-0.04, p=0.85)$. NA (centered around the individual mean) was a significant predictor of abstinence $(b=3.02, p=0.02)$. Results were mostly consistent in the separate logistic and Poisson models; however, weekend was significantly negatively related to abstinence in the logistic model $(b=-0.71, p=0.02)$.

The above models were re-run with trait affective instability, as measured via the PAIBOR AI subscale, included. This is not shown in a table, as results remained consistent. Twoway interactions between affective instability, NA, PA, and number of SCRs per minute were all non-significant. 


\section{EDA and Daily Fear as Predictors of Alcohol Use and Number of Drinks Consumed.}

Daily fear, PA, and SCRs per minute were entered as predictors in a zero-inflated Poisson mixed model. Interaction terms were included, but removed from the model if the p-value was greater than .25. For all subsequent models, the pattern of results did not change if interaction terms were removed from the model. The interaction between within-person (person centered) fear and $\mathrm{SCR} / \mathrm{min}$ was retained in the model.

Table 6 shows that there were no significant main effects in the zero-inflated Poisson mixed model. However, results of the multilevel logistic model suggest that weekend was significantly negatively related to abstaining from same-day alcohol use $(\mathrm{b}=-0.69, p=0.04)$. PA was negatively related to abstinence $(\mathrm{b}=-0.62, p=0.04)$ and fear (centered around the individual mean) was a significant predictor of abstinence $(\mathrm{b}=2.67, p=0.02)$.

EDA and Daily Hostility as Predictors of Alcohol Use and Number of Drinks Consumed. Daily hostility, PA, and SCRs per minute were entered as predictors in a zero-inflated Poisson mixed model. Interaction terms were included, but removed from the model if the p-value was greater than .25. No interactions were retained in the final model.

Table 7 shows that PA (as centered about the mean across all participants) was significantly negatively related to abstaining from alcohol use later that day $(b=-0.86, p=0.04)$, but unrelated to number of drinks consumed $(b=-0.12, p=0.58)$. Hostility (centered around the individual mean) was related to reduced number of drinks consumed during a drinking episode $(\mathrm{b}=-0.90, p=0.04)$. Results were mostly consistent in the separate logistic and Poisson models; however, in the logistic model, weekend was significantly negatively related to abstinence ( $b=-$ 
$0.74, p=0.03$ ) and hostility (centered around the individual mean) was related to abstinence $(\mathrm{b}=1.89, p=0.04)$.

EDA and Daily Sadness as Predictors of Alcohol Use and Number of Drinks Consumed. Daily sadness, PA, and SCRs per minute were entered as predictors in a zero-inflated Poisson mixed model. As shown in Table 8, PA (as centered about the mean across all participants) was significantly negatively related to abstaining from alcohol use that day $(b=-0.82, p=0.05)$, but unrelated to number of drinks consumed $(b=-0.11, p=0.62)$.

Also shown in Table 8, the estimates remain similar when a multilevel logistic model is used to predict alcohol abstinence; however, standard errors are reduced for some predictors, resulting in more significant findings. Significant findings remained significant and additional findings emerged. In particular, weekend was negatively associated with abstinence from alcohol $(b=-0.80, p=0.02)$ and sadness (centered about the individual's mean sadness across the week) was positively related to abstinence $(b=1.50, p=0.64)$. The pattern of results remained the same for the Poisson model.

EDA and Daily Negative Affect as Predictors of Maximum eBAC. The unconditional means model suggested that individuals differ in maximum level of eBAC and that eBAC also varies within-individual across days (Table 9). An intraclass correlation (ICC) indicating the proportion of total between-person variance was computed using the variance components of the unconditional means model $(\rho=0.19)$, suggesting that within-person variance explains a greater proportion of the model. Weekend versus weekday was not a significant predictor of maximum eBAC on drinking days $(b=0.02, p=0.21)$, but was retained in all models. 
Next, main effects and interaction terms were entered as predictors. Mean daily NA (before 4 PM), PA (before 4 PM), and number of skin conductance responses per minute per day (before $4 \mathrm{PM}$ ) were entered into the model, with each variable centered on the individual's average on the respective variable across the entire study period. Additionally, mean daily NA (before 4 PM), PA (before 4 PM), and number of skin conductance responses per minute per day (before 4 PM) were also centered on the mean for all individuals in the study. The model was estimated using random intercept only. Slopes were modeled as fixed due to limited observations. Additionally, a binary variable for weekend (1) versus weekday (0) was modeled as a fixed effect and entered as a predictor.

Additional covariates and interaction terms were included, but removed from the model if the p-value was greater than .25 . The interaction between within-person NA and SCR/min was included in the model, as was the interaction between within-person PA and SCR/min. Both interaction terms had a p-value greater than 0.25 and were removed from the final model.

As shown in Table 9, the only significant fixed effect in the final model was the main effect of NA (centered on mean NA across all participants). The relationship was negative, suggesting that when NA is low, the maximum eBAC is greater. No other main effects were significant. When all predictors were in the model, the intercept, or mean eBAC was 0.04 . EDA and Daily Fear as Predictors of Maximum eBAC. The same procedure from the previous model was followed for this model. Mean daily fear (before 4 PM), PA (before 4 PM), and number of skin conductance responses per minute per day (before $4 \mathrm{PM}$ ) were entered into the model, with each variable centered on the individual's average on the respective variable across the entire study period. Additionally, mean daily fear (before 4 PM), PA (before 4 PM), 
and number of skin conductance responses per minute per day (before $4 \mathrm{PM}$ ) were also centered on the mean for all individuals in the study.

Again, additional covariates and interaction terms were included, but removed from the model if the p-value was greater than .25 . The interaction between within-person fear and $\mathrm{SCR} / \mathrm{min}$ was included in the model, as was the interaction between within-person PA and $\mathrm{SCR} / \mathrm{min}$. Both interaction terms had a p-value greater than 0.25 and were removed from the final model.

As shown in Table 10, fear (centered on individual means) resulted in lower eBAC on drinking days $(\mathrm{b}=-0.19, p<0.01)$. There was also a trend for fear (as centered on grand mean) to be related to increased eBAC $(b=0.05, p=0.05)$. Lastly, there was a trend such that SCRs per minute were positively related to eBAC when centered on individual mean $(\mathrm{b}=0.01, p=0.06)$ and negatively related when centered on grand mean $(b=-0.01, p=0.06)$. When all predictors are in the model, the intercept, or mean eBAC was 0.04 .

EDA and Daily Hostility as Predictors of Maximum eBAC. The same procedure from the previous eBAC models was followed for this model. Mean daily hostility (before 4 PM), PA (before $4 \mathrm{PM}$ ), and number of skin conductance responses per minute per day (before $4 \mathrm{PM}$ ) were entered into the model, with each variable centered on the individual's average on the respective variable across the entire study period. Additionally, mean daily hostility (before 4 PM), PA (before 4 PM), and number of skin conductance responses per minute per day (before 4 PM) were also centered on the mean for all individuals in the study.

Again, additional covariates and interaction terms were included, but removed from the model if the p-value was greater than .25 . The interaction between within-person hostility and 
$\mathrm{SCR} / \mathrm{min}$ was included in the model, as was the interaction between within-person PA and $\mathrm{SCR} / \mathrm{min}$. The interaction between hostility and $\mathrm{SCR} / \mathrm{min}$ was significant and retained in the final model.

As shown in Table 11, hostility (centered on individual means) resulted in lower eBAC on drinking days $(b=-0.19, p<0.01)$. SCRs per minute was negatively related to eBAC when centered on grand mean $(\mathrm{b}=0.01, p=0.01)$. The interaction between hostility and SCRs per minute was negative, and as hostility and SCRs per minute decreased, eBAC increased $(b=-0.03$, $p=0.03$ ). When all predictors are in the model, the intercept, or mean eBAC was 0.04 .

EDA and Daily Sadness as Predictors of Maximum eBAC. Again, the same procedure for previous models was followed for this model. Mean daily sadness (before 4 PM), PA (before 4 PM), and number of skin conductance responses per minute per day (before 4 PM) were entered into the model, with each variable centered on the individual's average on the respective variable across the entire study period. Additionally, mean daily sadness (before 4 PM), PA (before 4 PM), and number of skin conductance responses per minute per day (before 4 PM) were also centered on the mean for all individuals in the study.

Again, additional covariates and interaction terms were included, but removed from the model if the p-value was greater than .25 . The interaction between within-person sadness and $\mathrm{SCR} / \mathrm{min}$ was included in the model, as was the interaction between within-person PA and $\mathrm{SCR} / \mathrm{min}$. Both interaction terms had a p-value greater than 0.25 and were removed from the final model.

As shown in Table 12, sadness (centered on grand mean) resulted in higher eBAC on drinking days $(b=0.08, p=0.01)$. There was a trend for sadness centered on the individual mean to 
show the reverse association $(b=-0.06, p=0.05)$. No other main effects were present. When all predictors are in the model, the intercept, or mean eBAC is 0.06 .

Affective Instability, EDA, and Daily NA as Predictors of Maximum eBAC. Daily NA, PA, number of skin conductance responses per minute per day, and trait affective instability (as assessed by the PAI-AI subscale) were entered into a model predicting maximum eBAC. The model was again estimated using random intercept only. Slopes were modeled as fixed.

The interaction between daily SCRs per minute and daily NA and PA, respectively, were included, as in previous models. Two-way interactions between affective instability and SCRs per minute and NA (both within person and between person) were also included. Again, a cutoff of p-value less than 0.25 was used for retention of interaction terms in the model. Based on this cut-off, two interaction terms were retained: 1) interaction between daily NA (person centered) and trait affective instability, and 2) interaction between daily SCRs per minute (person centered) and trait affective instability.

As shown in Table 13, one interaction term reached significance in the final model; the interaction between trait affective instability and daily person-centered NA was significant $(b=-$ $0.02, p=0.01)$. This association suggests individuals are more likely to have high eBACs, particularly when NA is low relative to the individual's own baseline. This is especially true for individuals high in AI. Of note, individuals with low AI have less variability in NA, restricting range and perhaps attenuating any existing relationship between NA and eBAC for this subgroup. Additionally, less frequent SCRs (grand mean centered) were predictive of higher eBACs $(b=-0.01, p=0.04)$ during drinking episodes. 


\section{DISCUSSION}

\section{Agreement Between Measures in Laboratory}

In general, the Q Sensor data appear to correlate positively and significantly with traditional, laboratory-based measures of skin conductance (e.g., Biopac). Associations are largest when the index of interest is number of SCRs per minute. The correlation is attenuated when the index of interest is SCL. Of note, the Q Sensor produced higher average SCL and lower average SCRs per minute than the Biopac-based measurement. Thus, it is possible that the Q Sensor is a reliable measure of change in EDA, but a poorer measure of overall SCL. Importantly, change in EDA is most significant for within-person assessments across time. Thus, Q Sensor SCRs per minute were considered an adequate measure for subsequent ambulatory analyses. However, Q Sensor results are tentative and require further replication, as baseline readings did not correspond with a traditional laboratory measure, which limits interpretability of the findings. It is also should be noted that there are limitations to using correlations as a measure of agreement, as they only describe the magnitude of the association and do not provide information regarding where the two measures agree. For example, it may be that the measures are fairly consistent at high levels of SCL, but not at lower levels of SCL. These associations are not accounted for in the presented correlations.

Additionally, there is greater opportunity for error in real-world settings which may have attenuated the "true" EDA effect. For example, participants remove the Q Sensor during sleeping hours and replace the Q Sensor on their wrists themselves the following morning. Variability in placement and proximity to the skin may impact results. Further, it is unclear how long the Q Sensor must be in contact with the skin before an accurate reading can be obtained, as the earliest 
indicator of agreement in the current study (baseline), showed poor agreement. This may reflect the degree to which the Q Sensor had time to "warm up." Future research is necessary to better understand the poor correspondence between measures at baseline. If the Q Sensor takes significant time to form accurate readings, anytime the Q Sensor is removed, this process may re-start.

\section{Ambulatory Assessment of Alcohol Use Outcomes}

When the outcome measure of interest was real-world alcohol use (i.e., any consumption versus no consumption), the results were mostly consistent across general NA, fear, hostility, and sadness. EDA was not a significant predictor of alcohol use alone or in interaction with affect in these models. In general, PA during the day was associated with any alcohol use in the evening and daytime NA (i.e., general, fear, hostility, sadness) was protective against use in the evening.

Daily EDA (number of skin conductance responses per minute) was significantly negatively related to maximum eBAC across several models; however, it was not related to alcohol use or number of drinks consumed. EDA did not interact with affect variables to predict drinking outcomes, except in one instance. When arousal was high and hostility was high during the day, maximum eBAC was reduced. Perhaps individuals are consciously or subconsciously initiating alcohol use to increase arousal on low arousal days; however, there was no evidence to suggest that alcohol use is preceded by same-day high arousal states. Importantly, it was hypothesized that high arousal would be associated with greater likelihood of use; however, the observed effect was in the opposite direction. Potential explanations for this finding are described more below. High arousal appears to be protective against alcohol use. It is worth noting that some research has found that as SCL increases, SCRs decrease; however, other work 
has shown increases in SCRs in high arousal states (see Boucsein, 2012). In the laboratory, Biopac-measured SCL correlated 0.56 with SCRs per minute $>0.01 \mu \mathrm{S}$ and 0.65 with SCRs per minute $>0.05 \mu \mathrm{S}$. Q Sensor-measured SCL correlated 0.38 with SCRs per minute $>0.01 \mu \mathrm{S}$ and 0.32 with SCRs per minute $>0.05 \mu \mathrm{S}$. Thus, based on laboratory data, it is unlikely that the findings of a lack of relation between SCRs per minute and alcohol use later in the evening were due to high SCL that accompanied infrequent SCRs.

The findings for alcohol use generally also held for number of drinks and maximum eBAC. However, there were some positive associations between NA and maximum eBAC. In particular, same-day NA (trend), fear (trend), and sadness (significant effect) scores were associated with higher eBACs on drinking days. Of note, this association was evident for grand mean centered affect only, suggesting that if on a particular day, you are higher in NA than most people typically are, you are more likely to have a higher eBAC that day. This could be a function of a person's general tendency for negative affect. If an individual is higher in NA on a single day than is generally true for most people, that individual may be more prone to NA on most days which suggests that trait NA may be more indicative of amount of alcohol use than same-day NA. When NA was higher than normal for the individual (person centered), NA was protective against or unrelated to alcohol use in all cases.

In sum, these results are consistent with previous work that fails to find a positive, proximal relationship between negative affect and alcohol consumption at the daily level. Given the widely popular notion that many individuals "drink to cope" with negative affect, the current study was designed in attempt to "uncover" when drinking in response to negative affect occurs. It was hypothesized that drinking would occur when negative affect was also accompanied by 
high levels of autonomic arousal, as indicated by skin conductance. However, autonomic arousal appears to follow the same pattern as negative affect, and in fact, high autonomic arousal coupled with negative emotion may result in increased avoidance of alcohol and/or social settings that involve alcohol. It is important to reiterate it was hypothesized that electrodermal responsivity would be higher prior to alcohol use episodes because, consistent with Fowles' (1980) theory, EDA is thought to be associated with avoidance of aversive states and alcohol could be used as one means of avoiding aversive states. Among a group of predominantly social drinkers, as is true in the current sample (roughly $83 \%$ of drinks in the current study were consumed in the presence of others), behavioral inhibition may result in social and/or risk avoidance which prevents engagement in settings that typically involve alcohol. Thus, an alternative interpretation of Fowles' theory may suggest that the behavioral inhibition system must be low in order for alcohol consumption to occur. Thus, in the current sample, disinhibition and positive affect may be the greatest proximal risk factors for alcohol consumption. Future research may examine this combination of risk factors directly in an ambulatory framework.

It was hypothesized that negative affect and high arousal contexts would pose the greatest risk for individuals high in affective instability. Interaction between trait affective instability and daily NA was not a significant predictor of alcohol use or number of drinks. However, eBAC, the interaction between trait affective instability and daily NA was a significant predictor of eBAC. Notably, increased NA was related to lower eBAC and this finding was stronger among individuals high in AI. Individuals high in AI show greater variability in NA, however. The association may not have been as strong for individuals with low AI because of the restricted range. 
Due to sample size limitations, it was not possible to break down the sample by high and low affective instability to determine if differential relations exist. However, it is worth noting that post-hoc analysis revealed that coping motives did significantly positively predict maximum eBAC in both a univariate model and with negative affect, positive affect, and skin conductance measures in the model. The interaction between coping motives and negative affect was not significant. This suggests that motivations to drink to cope with negative affect may predict increased alcohol consumption, irrespective of level of negative affect.

\section{Implications for Development of Alcohol Use Disorders}

Although several participants in the current study met criteria for an alcohol use disorder (31\%), participants were excluded if they exhibited withdrawal symptoms or had multiple failed attempts to cut down or quit drinking. Thus, this study oversampled individuals at high risk for severe alcohol use disorders or in early stages of the disease process, but did not include individuals with a severe alcohol use disorder at present. Research suggests that affect-alcohol relations change as addiction develops. For example, Koob and Le Moal (2001)'s allostatic model of addiction suggests that as addiction develops, the use of the substance becomes less rewarding and less positively reinforcing over time. Rather, the individual's baseline shifts such that use of the substance is necessary in order to feel "normal", and alcohol becomes more negatively reinforcing when the withdrawal process begins. Thus, positive reinforcement is generally associated with early stages of use, pre-addiction. This is consistent with the current findings as positive affect was a robust predictor of non-abstinence. Negative reinforcement appears to become more relevant for most individuals once addiction has set in. In light of this context, this study aimed to identify processes that occur in a unique sub-group in which 
negative reinforcement is a primary motivator early in the course of the addiction cycle. However, evidence for negative reinforcement was not found in the current study. Perhaps, negative affective states do place certain individuals at greater risk for developing an addiction, but proximal relations between negative affect and alcohol consumption only occur later in the addiction process.

Alternatively, these results may be interpreted as consistent with Volpicelli's (1987) endorphin depletion hypothesis. It is possible that same-day drinking is too proximal to the stressor to observe an effect, and perhaps the stressor is ongoing. Thus, perhaps the relationship between NA and alcohol consumption would be positive if examined over a different time frame. For example, next day drinking may be impacted by previous day negative affect/arousal and this is also an avenue for future research. In contrast, more proximal relations could also be examined, such as evening or concurrent affect. Of note, the current study focused on negative affect and arousal as precedents to alcohol use outcomes. However, correlations between alcohol use/number of drinks and affect/arousal measures within the same hour the drink was consumed showed some differential associations. Specifically, SCRs per minute showed a small, positive correlation with alcohol use concurrently $(r=0.11)$, positive affect was significantly positively related to alcohol use $(r=0.15)$, and negative affect was unrelated to alcohol use $(r=0.04)$. Thus, although not specifically examined in this study, it seems that arousal may increase more proximal to drinking episode; however, negative affect stills appears to be unrelated to drinking outcomes.

\section{Limitations and Future Directions}


The current results must be interpreted in light of limitations. First and most significantly, this study is underpowered to detect group differences, and therefore, differences between individuals with affective instability and without could not be formally examined as originally intended. A power analysis reveals that a sample size of 56 ( $n=28$ in each group) is required to be able to detect a medium effect with a 2-level model and an estimated 35 observations per person ( 5 surveys per day) when alpha is set at .05 and power set at .80 (Spybrook et al., 2011). In the current analyses, standard errors were large, particularly in the zero-inflated Poisson regression models. Thus, caution should be used when interpreting any single model. Rather, conclusions were made based on patterns replicated across models.

Second, it is worth mentioning that naturalistic assessments, such as those conducted in the ambulatory portion of the current study, provide valuable information regarding real-world behavior and the timing and context in which those behaviors occur. However, experimental control is sacrificed in these studies and the direction of causality can only be inferred based on temporal order of events. For example, if negative affect precedes alcohol consumption in the real-world, we may assume that alcohol consumption did not cause the negative affect, but we cannot definitively conclude that negative affect caused alcohol consumption. Of course, there are a number of possible alternative explanations that cannot be ruled out. Thus, future research should combine laboratory-based alcohol administration studies with real-world ambulatory assessments to further improve upon ecological validity and experimental control.

Third, participants in the current study did not start the ambulatory monitoring at the same time of day or day of week, reducing standardization across participants. In some ways, this may be an advantage as it reduces confounds between day of week and duration in study. 
However, if all participants had started on a Monday, for example, affect and EDA during the week could have been used as a predictor of weekend drinking activity, consistent with a cumulative stress model. Due to natural variations in weekend versus weekday drinking, this may be an avenue for future research.

Fourth, in many ways, the Q Sensor's measurement technique differs from the gold standard in the literature. For example, the Q Sensor applies a direct current through electrodes placed on the ventral side of the wrist. Boucsein and colleagues (2012) suggest that applying an alternating current is preferred because it prevents problems due to polarization. However, the direct current method is most commonly applied in research, so our method is consistent with most laboratory measures. Additionally, the use of $\mathrm{Ag} / \mathrm{AgCl}$ electrodes reduces (albeit, does not eliminate) the potential for polarization. However, the differences in Q Sensor technology also make the comparison with traditional laboratory-based measures an especially important area of inquiry.

Fifth, due to the clinical nature of the sample, almost half of participants were on psychiatric medications with anticholinergic properties. Highly-controlled laboratory studies examining EDA typically excludes participants with these medications, limiting generalizability of the results. We decided to retain participants on such medications to maintain a representative sample of the population of interest. However, doing so could have introduced error in the EDA analyses. However, a correlation between ambulatory SCRs per minute and anticholinergic burden was not observed in the current sample.

Finally, practically speaking, the utility of the current work is limited because the Q Sensor has been discontinued since the conception of this research project. As Kaplan and Stone 
(2013) note, a major challenge to validating ambulatory tools is that the available technology is constantly evolving for a variety of reasons, and the science behind the psychometric validation of these tools tends to lag behind. However, this research can provide a foundation for developers of new ambulatory electrodermal activity recording devices. Further, important information is obtained regarding relations between electrodermal activity and affect as predictors of alcohol use.

Future research should use more diverse samples, particularly samples that vary in age and gender. Affect and alcohol relations are thought to differ with age (Sher, 1991). Further, the current sample primarily consisted of women, limiting generalizability to men. Additionally, as described earlier, different physiological indicators may differentially predict affect and alcohol relations (e.g., heart rate variability and positive affect), so studies combining multiple physiological indicators should be used. Finally, a recent review by Picard, Fedor, and Ayzenberg (in press) has suggested that there are lateral differences in EDA measurement and that for more accurate assessment, EDA should be measured bilaterally (i.e., on both sides of the upper body). It is possible that different conclusions would have been made in the current research had bilateral measurements been available, and researchers should consider this in future studies.

\section{Summary and Conclusions}

In sum, this study demonstrated that ambulatory measurement of EDA is feasible, and correlations between ambulatory measures and traditional laboratory measures were moderate to large for SCRs, but small for SCL. This study suggests that positive affect remains the most important predictor of alcohol outcomes at the daily level, even among individuals with affective 
instability thought to be at greatest risk for "drinking to cope." It is possible that negative affectrelated drinking is associated with drinking in a delayed manner, consistent with Volpicelli's endorphin depletion hypothesis. Future work should examine the precise timing of affect, arousal, and alcohol relationships.

\section{TABLES AND FIGURES}

Table 1

Demographic and Psychiatric Characteristics of Sample

\begin{tabular}{|c|c|c|c|}
\hline & $\begin{array}{l}\text { Total Sample } \\
\quad(N=43)\end{array}$ & $\begin{array}{c}\text { AI Present } \\
(\mathrm{n}=24)\end{array}$ & $\begin{array}{c}\text { AI Absent } \\
(n=19)\end{array}$ \\
\hline \multicolumn{4}{|l|}{ Age } \\
\hline M & 26.67 & 27.13 & 26.11 \\
\hline SD & 7.67 & 7.49 & 8.06 \\
\hline$\%$ female & 83.7 & 79.2 & 89.5 \\
\hline \multicolumn{4}{|l|}{ Race (\%) } \\
\hline Caucasian & 83.7 & 91.7 & 73.7 \\
\hline African-American & 9.3 & 4.2 & 15.8 \\
\hline Asian/Asian-American & 4.7 & 4.2 & 5.3 \\
\hline American Indian/Alaska Native & 2.3 & 0.0 & 5.3 \\
\hline \multicolumn{4}{|l|}{ Ethnicity $(\%)$} \\
\hline Hispanic & 2.3 & 4.2 & 0.0 \\
\hline \multicolumn{4}{|l|}{ Marital Status (\%) } \\
\hline Single, Never Married & 67.4 & 70.8 & 63.2 \\
\hline Divorced or Separated & 11.6 & 20.9 & 0.0 \\
\hline Married or Cohabitating & 20.9 & 8.3 & 36.9 \\
\hline \multicolumn{4}{|l|}{ Income (\%) } \\
\hline Income less than $\$ 25,000(\%)$ & 62.8 & 70.8 & 52.6 \\
\hline Income $\$ 25,001-\$ 75,000(\%)$ & 11.7 & 12.5 & 10.6 \\
\hline Income greater than $\$ 75,001(\%)$ & 25.6 & 16.7 & 36.9 \\
\hline \multicolumn{4}{|l|}{ Highest Education Completed (\%) } \\
\hline High School or Equivalent & 2.3 & 0.0 & 5.3 \\
\hline Some Post HS Education & 51.2 & 45.8 & 57.9 \\
\hline Bachelor's Degree & 23.3 & 25.0 & 21.1 \\
\hline Graduate Degree & 23.3 & 29.2 & 15.8 \\
\hline
\end{tabular}




\begin{tabular}{lccc}
\hline $\begin{array}{l}\text { Currently employed (\%) } \\
\text { Treatment History (\%) }\end{array}$ & 79.1 & 79.2 & 78.9 \\
\hline $\begin{array}{l}\text { Previous psychotherapy } \\
\text { Previous psych hospitalizations }\end{array}$ & 79.1 & 95.8 & 57.9 \\
Medications (\%) & 18.6 & 29.2 & 5.3 \\
$\quad$ Any current medications & 69.8 & 83.3 & 52.6 \\
Current psychiatric medications & 58.1 & 79.2 & 21.1 \\
$\quad$ Medications with anticholinergic & 46.5 & 62.5 & 26.3 \\
properties & & & \\
Current DSM IV-TR Diagnoses (\%) & & & \\
Major Depressive Disorder & 9.5 & 17.4 & 0.0 \\
Bipolar I Disorder & 2.4 & 4.3 & 0.0 \\
Bipolar II Disorder & 4.8 & 8.7 & 0.0 \\
Borderline Personality Disorder & 32.6 & 58.3 & 0.0 \\
Generalized Anxiety Disorder & 31.7 & 47.8 & 10.5 \\
Social Phobia & 14.3 & 26.1 & 0.0 \\
Obsessive Compulsive Disorder & 11.9 & 21.7 & 0.0 \\
Posttraumatic Stress Disorder & 17.1 & 26.1 & 5.3 \\
Alcohol Use Disorder & 31.0 & 43.5 & 15.8 \\
Other Substance Use Disorder & 23.8 & 34.8 & 10.5 \\
\hline
\end{tabular}

Note. Axis I Disorder Information not available for 1 participant with AI. 
Table 2

Means, Standard Deviations, and Correlations Between Q Sensor and Biopac in Laboratory

\begin{tabular}{|c|c|c|c|}
\hline & Q Sensor & Biopac & Correlation \\
\hline EDA Variable & $\mathrm{M}(\mathrm{SD})$ & $\mathrm{M}(\mathrm{SD})$ & $r$ \\
\hline \multicolumn{4}{|l|}{ Baseline } \\
\hline SCL & $1.00(1.47)$ & $-0.01(0.05)$ & $-0.46 *$ \\
\hline $\mathrm{SCR}>.01 \mu \mathrm{S} / \mathrm{min}$ & $3.30(6.52)$ & $7.67(7.85)$ & 0.29 \\
\hline $\mathrm{SCR}>.05 \mu \mathrm{S} / \mathrm{min}$ & $0.73(1.93)$ & $3.53(4.73)$ & 0.25 \\
\hline \multicolumn{4}{|l|}{ Air Blast Amplitude } \\
\hline$\triangle \mathrm{SCL}$ & $0.56(0.93)$ & $1.52(1.42)$ & $0.37 *$ \\
\hline \multicolumn{4}{|l|}{ All Video Epochs } \\
\hline$\Delta \mathrm{SCL}$ & $0.27(1.05)$ & $0.02(0.08)$ & $0.31 *$ \\
\hline $\mathrm{SCR}>.01 \mu \mathrm{S} / \mathrm{min}$ & $3.35(4.63)$ & $12.61(8.22)$ & $0.60 *$ \\
\hline $\mathrm{SCR}>.05 \mu \mathrm{S} / \mathrm{min}$ & $0.98(1.85)$ & $7.28(6.76)$ & $0.53 *$ \\
\hline \multicolumn{4}{|l|}{ Fear Epoch } \\
\hline$\Delta \mathrm{SCL}$ & $0.35(1.08)$ & $0.02(0.10)$ & $0.32 *$ \\
\hline $\mathrm{SCR}>.01 \mu \mathrm{S} / \mathrm{min}$ & $2.90(4.22)^{\mathrm{a}}$ & $12.88(7.43)^{\mathrm{a}}$ & $0.55^{*}$ \\
\hline $\mathrm{SCR}>.05 \mu \mathrm{S} / \mathrm{min}$ & $0.67(1.37)$ & $7.52(6.58)^{\mathrm{a}}$ & $0.40 *$ \\
\hline \multicolumn{4}{|l|}{ Sadness Epoch } \\
\hline$\triangle \mathrm{SCL}$ & $0.22(1.11)$ & $0.01(0.07)$ & $0.42 *$ \\
\hline $\mathrm{SCR}>.01 \mu \mathrm{S} / \mathrm{min}$ & $2.83(3.91)^{\mathrm{a}}$ & $11.24(7.88)^{\mathrm{a}}$ & $0.64 *$ \\
\hline $\mathrm{SCR}>.05 \mu \mathrm{S} / \mathrm{min}$ & $0.73(1.35)^{\mathrm{a}}$ & $6.13(6.01)^{\mathrm{a}}$ & $0.51 *$ \\
\hline \multicolumn{4}{|l|}{ Anger Epoch } \\
\hline$\triangle \mathrm{SCL}$ & $0.33(1.04)$ & $0.01(0.07)$ & $0.43 *$ \\
\hline $\mathrm{SCR}>.01 \mu \mathrm{S} / \mathrm{min}$ & $3.66(5.63)^{\mathrm{a}}$ & $11.61(8.80)^{\mathrm{a}}$ & $0.55^{*}$ \\
\hline $\mathrm{SCR}>.05 \mu \mathrm{S} / \mathrm{min}$ & $1.11(2.29)^{\mathrm{a}}$ & $6.74(6.92)^{\mathrm{a}}$ & $0.56^{*}$ \\
\hline \multicolumn{4}{|l|}{ Happy Epoch } \\
\hline$\triangle \mathrm{SCL}$ & $0.25(1.07)$ & $0.04(0.07)$ & 0.20 \\
\hline $\mathrm{SCR}>.01 \mu \mathrm{S} / \mathrm{min}$ & $4.44(5.35)^{\mathrm{a}}$ & $15.82(8.58)^{\mathrm{a}}$ & $0.66^{*}$ \\
\hline $\mathrm{SCR}>.05 \mu \mathrm{S} / \mathrm{min}$ & $1.51(2.35)^{\mathrm{a}}$ & $9.80(7.72)^{\mathrm{a}}$ & $0.58 *$ \\
\hline \multicolumn{4}{|l|}{ Neutral Epoch } \\
\hline$\triangle \mathrm{SCL}$ & $0.21(1.01)$ & $0.01(0.06)$ & 0.12 \\
\hline $\mathrm{SCR}>.01 \mu \mathrm{S} / \mathrm{min}$ & $2.93(3.82)^{\mathrm{a}}$ & $11.51(7.98)^{\mathrm{a}}$ & $0.60 *$ \\
\hline $\mathrm{SCR}>.05 \mu \mathrm{S} / \mathrm{min}$ & $0.90(1.61)^{\mathrm{a}}$ & $6.20(6.18)^{\mathrm{a}}$ & $0.52 *$ \\
\hline
\end{tabular}

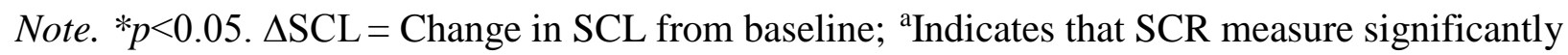
differs from baseline measure from same instrument. Averages and correlations are based on $\mathrm{n}=30$. 
Table 3a

Correlations Between Daily Ambulatory Skin Conductance Variables

\begin{tabular}{lcccc}
\hline EDA Variable & a & b & c & d \\
\hline (a) SCR $>.01 \mu \mathrm{S} / \min$ & -- & & & \\
(b) Resid SCR $>.01 \mu \mathrm{S} / \min$ & $.78^{*}$ & -- & & \\
(c) $\mathrm{SCR}>.05 \mu \mathrm{S} / \mathrm{min}$ & $.94^{*}$ & $.70^{*}$ & -- & \\
(d) Resid SCR $>.05 \mu \mathrm{S} / \mathrm{min}$ & $.76^{*}$ & $.95^{*}$ & $.76^{*}$ & -- \\
\hline
\end{tabular}

Note. Correlations are based on 194 days of EDA data across 34 participants. Resid SCR refers to the residual of SCR after variance associated with activity removed.

Table 3b

Correlations Between Daily Ambulatory Skin Conductance Variables and Ambulatory Affect Variables

\begin{tabular}{lcc}
\hline Affect Variable & $\begin{array}{c}\text { Resid SCR }>.01 \\
\mu \mathrm{S} / \mathrm{min}\end{array}$ & $\begin{array}{c}\text { Resid SCR }>.05 \\
\mu \mathrm{S} / \mathrm{min}\end{array}$ \\
\hline Positive Affect & $-0.15^{*}$ & -0.14 \\
Negative Affect & -0.04 & -0.03 \\
Fear & -0.01 & -0.02 \\
Hostility & 0.05 & 0.08 \\
Sadness & $<-0.01$ & 0.01 \\
\hline
\end{tabular}

Note. *indicates $\mathrm{p}<.05$. Correlations are based on 194 days of EDA data across 34 participants. Resid SCR refers to the residual of SCR after variance associated with activity removed. 
Table 4

Correlations Between Ambulatory Affect, Ambulatory Skin Conductance, and Retrospective Self-Report

\begin{tabular}{lccccccc}
\hline & $\begin{array}{c}\text { Resid SCR }> \\
.01 \mu \mathrm{S} / \mathrm{min}\end{array}$ & $\begin{array}{c}\text { Resid SCR }> \\
.05 \mu \mathrm{S} / \mathrm{min}\end{array}$ & $\begin{array}{c}\text { Positive } \\
\text { Affect }\end{array}$ & $\begin{array}{c}\text { Negative } \\
\text { Affect }\end{array}$ & Fear & Hostility & Sadness \\
\hline \multicolumn{1}{c}{ Self-Report } & & & & & & & \\
\hline DERS-Total & 0.21 & $0.33^{\dagger}$ & $-0.37^{*}$ & $0.58^{*}$ & $0.48^{*}$ & $0.43^{*}$ & $0.35^{*}$ \\
PAI-BOR Total & 0.09 & 0.21 & $-0.32^{\dagger}$ & $0.67^{*}$ & $0.56^{*}$ & $0.63^{*}$ & $0.68^{*}$ \\
PAI-BOR AI & 0.14 & 0.25 & $-0.38^{\dagger}$ & $0.59^{*}$ & $0.53^{*}$ & $0.59^{*}$ & $0.56^{*}$ \\
PAI-BOR Self-Harm & -0.03 & 0.11 & -0.22 & $0.61^{*}$ & $0.48^{*}$ & $0.55^{*}$ & $0.54^{*}$ \\
DASS-Depression & 0.24 & $0.34^{\dagger}$ & -0.23 & $0.54^{*}$ & $0.41^{*}$ & $0.56^{*}$ & $0.75^{*}$ \\
DASS-Anxiety & 0.27 & $0.37^{*}$ & -0.13 & $0.61^{*}$ & $0.65^{*}$ & $0.55^{*}$ & $0.47^{*}$ \\
DASS-Stress & 0.16 & 0.22 & -0.15 & $0.57^{*}$ & $0.52^{*}$ & $0.57^{*}$ & $0.34^{\dagger}$ \\
DMQ- Coping & -0.01 & 0.00 & 0.03 & $0.72^{*}$ & $0.65^{*}$ & $0.72^{*}$ & $0.75^{*}$ \\
DMQ- Enhancement & $-0.34^{*}$ & $-0.33^{\dagger}$ & 0.26 & 0.25 & 0.22 & 0.21 & $0.33^{\dagger}$ \\
DMQ- Social & -0.05 & 0.01 & 0.19 & 0.15 & -0.02 & 0.21 & 0.23 \\
DMQ- Conformity & -0.06 & 0.02 & 0.09 & 0.22 & 0.04 & 0.26 & $0.31^{\dagger}$ \\
\hline
\end{tabular}

Note. $*$ indicates $\mathrm{p}<.05 .{ }^{\dagger}$ denotes $\mathrm{p}<0.10$ DERS-Total=Difficulties in Emotion Regulation Total Score; PAI-BOR Personality Assessment Inventory Borderline Subscale; AI=Affective Instability; DASS= Depression Anxiety Stress Scales; DMQ= Drinking Motives Questionnaire. 
Table 5

Zero-Inflated Poisson (ZIP) Multilevel Model: Negative Affect, Positive Affect, and Electrodermal Activity as Predictors of Number of Drinks Per Day

\begin{tabular}{|c|c|c|c|c|c|c|}
\hline & \multicolumn{2}{|c|}{ Null ZIP Model } & \multicolumn{2}{|c|}{$\begin{array}{c}\text { Multivariate } \\
\text { ZIP } \\
\text { Model } \\
\end{array}$} & \multicolumn{2}{|c|}{$\begin{array}{c}\text { Separate } \\
\text { Multivariate } \\
\text { Models } \\
\end{array}$} \\
\hline & Value & SE & Value & SE & Value & SE \\
\hline Logistic Part & & & & & Logistic & del \\
\hline Intercept & 0.02 & 0.17 & 0.19 & 0.28 & $0.65 *$ & 0.20 \\
\hline Weekend & & & -0.59 & 0.45 & $-0.71 *$ & 0.35 \\
\hline NA grand mean centered & & & 0.11 & 0.81 & 0.08 & 0.65 \\
\hline PA grand mean centered & & & $-0.91 *$ & 0.42 & $-0.71 *$ & 0.30 \\
\hline $\mathrm{rSCR} / \mathrm{min}$ mean centered & & & -0.09 & 0.08 & -0.07 & 0.06 \\
\hline NA person centered & & & $3.02 *$ & 1.26 & $3.02 *$ & 1.05 \\
\hline PA person centered & & & 0.85 & 0.64 & 0.68 & 0.50 \\
\hline $\begin{array}{l}\mathrm{rSCR} / \mathrm{min} \text { person } \\
\text { centered }\end{array}$ & & & -0.10 & 0.10 & $<-0.01$ & 0.07 \\
\hline Poisson Part & & & & & $\begin{array}{l}\text { Poisson } 1 \\
\text { (Drinking } \\
\text { Only) }\end{array}$ & $\begin{array}{l}\text { del } \\
\text { pisodes }\end{array}$ \\
\hline Intercept & $0.76^{*}$ & 0.12 & $0.55^{*}$ & 0.16 & $0.80^{*}$ & 0.11 \\
\hline Weekend & & & $0.36^{\dagger}$ & 0.20 & 0.24 & 0.16 \\
\hline NA grand mean centered & & & 0.29 & 0.40 & 0.26 & 0.31 \\
\hline PA grand mean centered & & & -0.04 & 0.22 & -0.03 & 0.16 \\
\hline $\mathrm{rSCR} / \mathrm{min}$ mean centered & & & $<0.01$ & 0.04 & $<-0.01$ & 0.03 \\
\hline NA person centered & & & -0.71 & 0.44 & -0.51 & 0.34 \\
\hline PA person centered & & & 0.20 & 0.32 & 0.19 & 0.25 \\
\hline $\begin{array}{l}\text { rSCR/min person } \\
\text { centered }\end{array}$ & & & $-0.07^{\dagger}$ & 0.05 & -0.03 & 0.04 \\
\hline
\end{tabular}

Note. $*$ denotes $p$-values less than $0.05 .{ }^{\dagger}$ denotes a non-significant effect less than 0.10 . Only intercept modeled as random. Logistic portion is predicting drink=0 (abstinence), with higher values indicating a greater likelihood of abstaining from alcohol that day. The Poisson portion predicts number of drinks, with higher values indicating more drinking that day. 
Table 6

Zero-Inflated Poisson Multilevel Model: Fear, Positive Affect, and Electrodermal Activity as Predictors of Number of Drinks Per Day

\begin{tabular}{|c|c|c|c|c|c|c|}
\hline & \multicolumn{2}{|c|}{ Null ZIP Model } & \multicolumn{2}{|c|}{$\begin{array}{c}\text { Multivariate } \\
\text { ZIP } \\
\text { Model }\end{array}$} & \multicolumn{2}{|c|}{$\begin{array}{c}\text { Separate } \\
\text { Multivariate } \\
\text { Models }\end{array}$} \\
\hline & Value & SE & Value & SE & Value & SE \\
\hline Logistic Part & & & & & Logistic & \\
\hline Intercept & 0.02 & 0.17 & 0.01 & 0.34 & $0.59 *$ & 0.20 \\
\hline Weekend & & & -0.53 & 0.46 & $-0.69 *$ & 0.34 \\
\hline Fear grand mean centered & & & 0.26 & 0.55 & 0.07 & 0.47 \\
\hline PA grand mean centered & & & $-0.97^{\dagger}$ & 0.48 & $-0.62 *$ & -0.08 \\
\hline $\mathrm{rSCR} / \mathrm{min}$ mean centered & & & -0.13 & 0.09 & -0.08 & 0.05 \\
\hline Fear person centered & & & 2.27 & 1.35 & $2.67 *$ & 1.13 \\
\hline PA person centered & & & 0.45 & 0.66 & 0.36 & 0.49 \\
\hline $\begin{array}{l}\text { rSCR/min person } \\
\text { centered }\end{array}$ & & & -0.15 & 0.12 & $<0.01$ & 0.07 \\
\hline $\begin{array}{l}\text { Fear*rSCR/min person } \\
\text { centered }\end{array}$ & & & -0.79 & 0.56 & -0.25 & 0.30 \\
\hline Poisson Part & & & & & $\begin{array}{l}\text { Poisson } \\
\text { (Drinkin } \\
\text { Only) }\end{array}$ & $\begin{array}{l}\text { lel } \\
\text { oisodes }\end{array}$ \\
\hline Intercept & $0.76^{*}$ & 0.12 & $0.55^{*}$ & 0.16 & $0.82 *$ & 0.11 \\
\hline Weekend & & & $0.41^{\dagger}$ & 0.20 & 0.24 & 0.16 \\
\hline Fear grand mean centered & & & 0.36 & 0.27 & 0.30 & 0.20 \\
\hline PA grand mean centered & & & -0.08 & 0.23 & -0.03 & 0.16 \\
\hline $\mathrm{rSCR} / \mathrm{min}$ mean centered & & & $<-0.01$ & 0.04 & $<-0.01$ & 0.03 \\
\hline Fear person centered & & & -0.52 & 0.43 & -0.38 & 0.34 \\
\hline PA person centered & & & 0.15 & 0.33 & 0.18 & 0.26 \\
\hline $\begin{array}{l}\mathrm{rSCR} / \mathrm{min} \text { person } \\
\text { centered }\end{array}$ & & & -0.08 & 0.05 & -0.03 & 0.04 \\
\hline $\begin{array}{l}\text { Fear*rSCR/min person } \\
\text { centered }\end{array}$ & & & $-0.12^{\dagger}$ & 0.16 & -0.06 & 0.13 \\
\hline
\end{tabular}

Note. $*$ denotes $p$-values less than $0.05 .{ }^{\dagger}$ denotes a non-significant effect less than 0.10 . Only intercept modeled as random. Logistic portion is predicting drink $=0$ (abstinence), with higher values indicating a greater likelihood of abstaining from alcohol that day. The Poisson portion predicts number of drinks, with higher values indicating more drinking that day. 
Table 7

Zero-Inflated Poisson Multilevel Model: Hostility, Positive Affect, and Electrodermal Activity as Predictors of Number of Drinks Per Day

\begin{tabular}{|c|c|c|c|c|c|c|}
\hline & \multicolumn{2}{|c|}{ Null ZIP Model } & \multicolumn{2}{|c|}{$\begin{array}{c}\text { Multivariate } \\
\text { ZIP } \\
\text { Model }\end{array}$} & \multicolumn{2}{|c|}{$\begin{array}{c}\text { Separate Multivariate } \\
\text { Models }\end{array}$} \\
\hline & Value & $\mathbf{S E}$ & Value & SE & Value & SE \\
\hline Logistic Part & & & & & Logistic & del \\
\hline Intercept & 0.02 & 0.17 & 0.16 & 0.29 & $0.65^{*}$ & 0.20 \\
\hline Weekend & & & -0.66 & 0.45 & $-0.74 *$ & 0.34 \\
\hline $\begin{array}{l}\text { Host grand mean } \\
\text { centered }\end{array}$ & & & -0.02 & 1.35 & 0.33 & 0.92 \\
\hline PA grand mean centered & & & $-0.86^{*}$ & 0.41 & $-0.61 *$ & 0.29 \\
\hline $\mathrm{rSCR} / \mathrm{min}$ mean centered & & & -0.10 & 0.08 & -0.07 & 0.06 \\
\hline Host person centered & & & 1.52 & 1.09 & $1.89 *$ & 0.90 \\
\hline PA person centered & & & 0.83 & 0.65 & 0.62 & 0.49 \\
\hline $\begin{array}{l}\mathrm{rSCR} / \mathrm{min} \text { person } \\
\text { centered }\end{array}$ & & & -0.10 & 0.10 & -0.02 & 0.07 \\
\hline Poisson Part & & & & & $\begin{array}{l}\text { Poisson } \\
\text { (Drinkin } \\
\text { Only) }\end{array}$ & $\begin{array}{l}\text { del } \\
\text { pisodes }\end{array}$ \\
\hline Intercept & $0.76^{*}$ & 0.12 & $0.53 *$ & 0.16 & $0.79 *$ & 0.11 \\
\hline Weekend & & & $0.34^{\dagger}$ & 0.20 & 0.23 & 0.16 \\
\hline $\begin{array}{l}\text { Host grand mean } \\
\text { centered }\end{array}$ & & & -0.01 & 0.72 & 0.11 & 0.53 \\
\hline PA grand mean centered & & & -0.12 & 0.21 & -0.08 & 0.16 \\
\hline $\mathrm{rSCR} / \mathrm{min}$ mean centered & & & -0.01 & 0.04 & -0.01 & 0.03 \\
\hline Host person centered & & & $-0.90 *$ & 0.43 & $-0.64^{\dagger}$ & 0.33 \\
\hline PA person centered & & & 0.26 & 0.32 & 0.22 & 0.25 \\
\hline $\begin{array}{l}\mathrm{rSCR} / \mathrm{min} \text { person } \\
\text { centered }\end{array}$ & & & $-0.05^{\dagger}$ & 0.05 & -0.02 & 0.04 \\
\hline
\end{tabular}

Note. *denotes $p$-values less than 0.05 . ${ }^{\dagger}$ denotes a non-significant effect less than 0.10 . Only intercept modeled as random. Logistic portion is predicting drink $=0$ (abstinence), with higher values indicating a greater likelihood of abstaining from alcohol that day. The Poisson portion predicts number of drinks, with higher values indicating more drinking that day. 
Table 8

Zero-Inflated Poisson Multilevel Model: Sadness, Positive Affect, and Electrodermal Activity as Predictors of Number of Drinks Per Day

\begin{tabular}{|c|c|c|c|c|c|c|}
\hline & \multicolumn{2}{|c|}{ Null ZIP Model } & \multicolumn{2}{|c|}{$\begin{array}{c}\text { Multivariate } \\
\text { ZIP } \\
\text { Model }\end{array}$} & \multicolumn{2}{|c|}{$\begin{array}{c}\text { Separate Multivariate } \\
\text { Models }\end{array}$} \\
\hline & Value & SE & Value & SE & Value & SE \\
\hline Logistic Part & & & & & Logistic & \\
\hline Intercept & 0.02 & 0.17 & 0.17 & 0.29 & $0.64 *$ & 0.19 \\
\hline Weekend & & & -0.76 & 0.46 & $-0.80 *$ & 0.35 \\
\hline Sad grand mean centered & & & -0.03 & 0.56 & 0.01 & 0.41 \\
\hline PA grand mean centered & & & $-0.82 *$ & 0.40 & $-0.60 *$ & 0.29 \\
\hline $\mathrm{rSCR} / \mathrm{min}$ mean centered & & & -0.10 & 0.07 & -0.08 & 0.06 \\
\hline Sad person centered & & & 1.34 & 0.82 & $1.50 *$ & 0.64 \\
\hline PA person centered & & & 1.02 & 0.70 & 0.76 & 0.50 \\
\hline $\begin{array}{l}\mathrm{rSCR} / \mathrm{min} \text { person } \\
\text { centered }\end{array}$ & & & -0.08 & 0.10 & 0.01 & 0.07 \\
\hline Poisson Part & & & & & $\begin{array}{l}\text { Poisson } \\
\text { (Drinkin }\end{array}$ & odes Only) \\
\hline Intercept & $0.76^{*}$ & 0.12 & $0.54 *$ & 0.16 & $0.81 *$ & 0.12 \\
\hline Weekend & & & $0.38^{\dagger}$ & 0.20 & $0.27^{\dagger}$ & 0.16 \\
\hline Sad grand mean centered & & & 0.08 & 0.31 & 0.14 & 0.23 \\
\hline PA grand mean centered & & & -0.11 & 0.22 & -0.09 & 0.16 \\
\hline $\mathrm{rSCR} / \mathrm{min}$ mean centered & & & $<0.01$ & 0.04 & $<-0.01$ & 0.03 \\
\hline Sad person centered & & & -0.48 & 0.33 & -0.26 & 0.26 \\
\hline PA person centered & & & 0.24 & 0.35 & 0.22 & 0.27 \\
\hline $\begin{array}{l}\mathrm{rSCR} / \mathrm{min} \text { person } \\
\text { centered }\end{array}$ & & & -0.07 & 0.05 & -0.04 & 0.04 \\
\hline
\end{tabular}

Note. *denotes $p$-values less than 0.05 . ${ }^{\dagger}$ denotes a non-significant effect less than 0.10 . Only intercept modeled as random. Logistic portion is predicting drink=0 (abstinence), with higher values indicating a greater likelihood of abstaining from alcohol that day. The Poisson portion predicts number of drinks, with higher values indicating more drinking that day. 
Table 9

Negative Affect, Positive Affect, and Electrodermal Activity as Predictors of Maximum Estimated Blood Alcohol Concentration

\begin{tabular}{|c|c|c|c|c|}
\hline & \multicolumn{2}{|c|}{ Null Model } & \multicolumn{2}{|c|}{ Full Model } \\
\hline & Value & SE & Value & SE \\
\hline \multicolumn{5}{|l|}{ Fixed effects } \\
\hline Intercept & $0.05^{*}$ & 0.01 & $0.04 *$ & 0.01 \\
\hline Weekend & & & 0.02 & 0.02 \\
\hline $\begin{array}{l}\text { NA grand mean } \\
\text { centered }\end{array}$ & & & $0.07^{\dagger}$ & 0.04 \\
\hline PA grand mean centered & & & 0.03 & 0.02 \\
\hline $\begin{array}{l}\mathrm{rSCR} / \mathrm{min} \text { mean } \\
\text { centered }\end{array}$ & & & $-0.01^{\dagger}$ & $<0.01$ \\
\hline NA person centered & & & $-0.16^{*}$ & 0.04 \\
\hline PA person centered & & & 0.02 & 0.03 \\
\hline $\begin{array}{l}\mathrm{rSCR} / \mathrm{min} \text { person } \\
\text { centered }\end{array}$ & & & 0.01 & $<0.01$ \\
\hline \multicolumn{5}{|l|}{ Random effects } \\
\hline$\frac{\tau^{2}{ }_{0} \text { (between) }}{4}$ & $<0.01 *$ & $<0.01$ & $<0.01 *$ & $<0.01$ \\
\hline$\sigma^{2}$ (within) & $<0.01 *$ & $<0.01$ & $<0.01 *$ & $<0.01$ \\
\hline
\end{tabular}


Table 10

Fear, Positive Affect, and Electrodermal Activity as Predictors of Maximum Estimated Blood Alcohol Concentration

\begin{tabular}{lcccc}
\hline & \multicolumn{2}{c}{ Null Model } & \multicolumn{2}{c}{ Full Model } \\
\hline & Value & SE & Value & SE \\
\hline Fixed effects & & & & \\
\hline Intercept & $0.05^{*}$ & 0.01 & $0.04^{*}$ & 0.01 \\
Weekend & & & 0.01 & 0.02 \\
Fear grand mean & & $0.05^{\dagger}$ & 0.02 \\
centered & & 0.02 & 0.02 \\
PA grand mean centered & & & $-0.01^{\dagger}$ & $<0.01$ \\
rSCR/min mean & & & & \\
centered & & & $-0.19^{*}$ & 0.04 \\
Fear person centered & & & 0.03 & 0.03 \\
PA person centered & & & $0.01^{\dagger}$ & $<0.01$ \\
rSCR/min person & & & & \\
centered & & & & \\
\hline Random effects & & & & \\
\hline$\tau_{0}^{2}$ (between) & $<0.01 *$ & $<0.01$ & $<0.01^{*}$ & $<0.01$ \\
$\sigma^{2}$ (within) & $<0.01 *$ & $<0.01$ & $<0.01^{*}$ & $<0.01$ \\
\hline
\end{tabular}

Note. $*$ denotes $p$-values less than $0.05 .{ }^{\dagger}$ denotes a non-significant effect less than 0.10 . Only intercept modeled as random. 
Table 11

Hostility, Positive Affect, and Electrodermal Activity as Predictors of Maximum Estimated Blood Alcohol Concentration

\begin{tabular}{|c|c|c|c|c|}
\hline & \multicolumn{2}{|c|}{ Null Model } & \multicolumn{2}{|c|}{ Full Model } \\
\hline & Value & SE & Value & SE \\
\hline \multicolumn{5}{|l|}{ Fixed effects } \\
\hline Intercept & $0.05^{*}$ & 0.01 & $0.04 *$ & 0.01 \\
\hline Weekend & & & 0.02 & 0.02 \\
\hline $\begin{array}{l}\text { Host grand mean } \\
\text { centered }\end{array}$ & & & 0.05 & 0.05 \\
\hline PA grand mean centered & & & 0.02 & 0.02 \\
\hline $\begin{array}{l}\mathrm{rSCR} / \mathrm{min} \text { mean } \\
\text { centered }\end{array}$ & & & $-0.01 *$ & $<0.01$ \\
\hline Host person centered & & & $-0.19 *$ & 0.04 \\
\hline PA person centered & & & 0.02 & 0.03 \\
\hline $\begin{array}{l}\mathrm{rSCR} / \mathrm{min} \text { person } \\
\text { centered }\end{array}$ & & & 0.01 & $<0.01$ \\
\hline $\begin{array}{l}\text { Host*rSCR/min person } \\
\text { centered }\end{array}$ & & & $-0.03 *$ & 0.01 \\
\hline \multicolumn{5}{|l|}{ Random effects } \\
\hline$\tau_{0}^{2}$ (between) & $<0.01 *$ & $<0.01$ & $<0.01$ & $<0.01$ \\
\hline$\sigma^{2}($ within $)$ & $<0.01 *$ & $<0.01$ & $<0.01 *$ & $<0.01$ \\
\hline
\end{tabular}


Table 12

Sadness, Positive Affect, and Electrodermal Activity as Predictors of Maximum Estimated Blood Alcohol Concentration

\begin{tabular}{|c|c|c|c|c|}
\hline & \multicolumn{2}{|c|}{ Null Model } & \multicolumn{2}{|c|}{ Full Model } \\
\hline & Value & SE & Value & SE \\
\hline \multicolumn{5}{|l|}{ Fixed effects } \\
\hline Intercept & $0.05^{*}$ & 0.01 & $0.06 *$ & 0.01 \\
\hline Weekend & & & 0.02 & 0.02 \\
\hline $\begin{array}{l}\text { Sadn grand mean } \\
\text { centered }\end{array}$ & & & $0.08 *$ & 0.03 \\
\hline PA grand mean centered & & & 0.01 & 0.02 \\
\hline $\begin{array}{l}\mathrm{rSCR} / \mathrm{min} \text { mean } \\
\text { centered }\end{array}$ & & & -0.01 & $<0.01$ \\
\hline Sadn person centered & & & $-0.06^{\dagger}$ & 0.03 \\
\hline PA person centered & & & 0.04 & 0.03 \\
\hline $\begin{array}{l}\mathrm{rSCR} / \mathrm{min} \text { person } \\
\text { centered }\end{array}$ & & & 0.01 & $<0.01$ \\
\hline \multicolumn{5}{|l|}{ Random effects } \\
\hline$\tau_{0}^{2}$ (between) & $<0.01 *$ & $<0.01$ & $<0.01$ & $<0.01$ \\
\hline$\sigma^{2}$ (within) & $<0.01 *$ & $<0.01$ & $<0.01 *$ & $<0.01$ \\
\hline
\end{tabular}


Table 13

Trait Affective Instability, Negative Affect, Positive Affect, and Electrodermal Activity as Predictors of Maximum Estimated Blood Alcohol Concentration

\begin{tabular}{|c|c|c|c|c|}
\hline & \multicolumn{2}{|c|}{ Null Model } & \multicolumn{2}{|c|}{ Full Model } \\
\hline & Value & SE & Value & SE \\
\hline \multicolumn{5}{|l|}{ Fixed effects } \\
\hline Intercept & $0.05^{*}$ & 0.01 & 0.03 & 0.02 \\
\hline Weekend & & & 0.02 & 0.02 \\
\hline PAI-AI & & & $<0.01$ & $<0.01$ \\
\hline $\begin{array}{l}\text { NA grand mean } \\
\text { centered }\end{array}$ & & & $<-0.01$ & 0.04 \\
\hline PA grand mean centered & & & 0.02 & 0.02 \\
\hline $\begin{array}{l}\mathrm{rSCR} / \mathrm{min} \text { mean } \\
\text { centered }\end{array}$ & & & $-0.01 *$ & $<0.01$ \\
\hline NA person centered & & & -0.14 & 0.11 \\
\hline PA person centered & & & 0.02 & 0.03 \\
\hline $\begin{array}{l}\mathrm{rSCR} / \mathrm{min} \text { person } \\
\text { centered }\end{array}$ & & & $<0.01$ & 0.01 \\
\hline $\begin{array}{l}\text { PAI-AI*NA person } \\
\text { centered }\end{array}$ & & & $-0.02 *$ & 0.01 \\
\hline $\begin{array}{l}\mathrm{PAI}-\mathrm{AI} * \mathrm{rSCR} / \mathrm{min} \\
\text { person centered }\end{array}$ & & & $<0.01$ & $<0.01$ \\
\hline \multicolumn{5}{|l|}{ Random effects } \\
\hline$\overline{\tau^{2}{ }_{0} \text { (between) }}$ & $<0.01 *$ & $<0.01$ & $<0.01$ & $<0.01$ \\
\hline$\sigma^{2}$ (within) & $<0.01 *$ & $<0.01$ & $<0.01 *$ & $<0.01$ \\
\hline
\end{tabular}

Note. $*$ denotes $p$-values less than 0.05 . ${ }^{\dagger}$ denotes a non-significant effect less than 0.10 . Only intercept modeled as random.

PAI-AI=Personality Assessment Inventory- Affective Instability Subscale 
Figure 1

Drink Reports by Day of Week

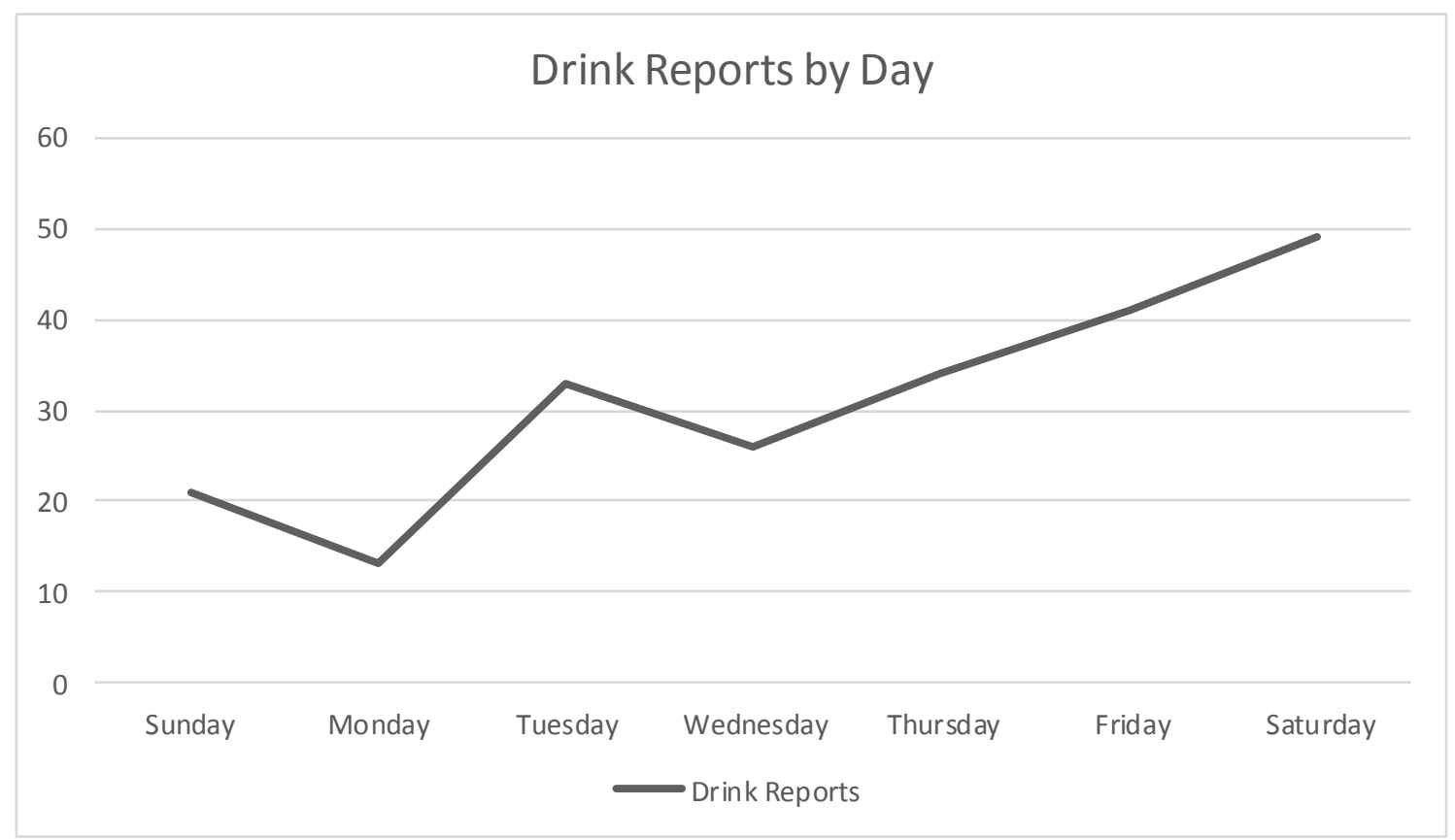


Figure 2

Drink Reports by Time of Day

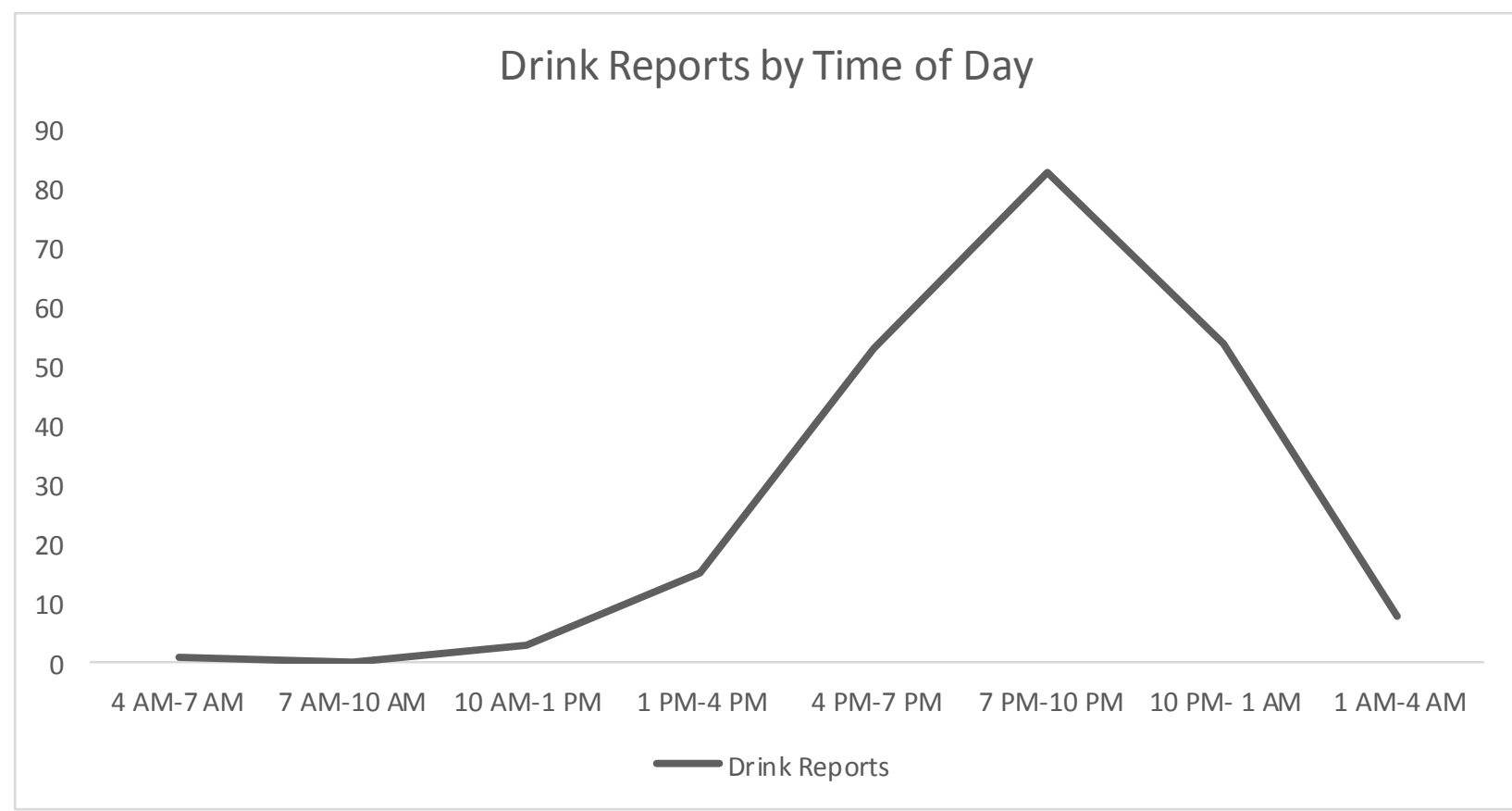




\section{REFERENCES}

American Psychiatric Association. (2013). Diagnostic and statistical manual of mental disorders (5th ed.). Washington, DC: Author.

Armeli, S., Conner, T. S., Cullum, J., \& Tennen, H. (2010). A longitudinal analysis of drinking motives moderating the negative affect-drinking association among college students. Psychology of Addictive Behaviors, 24, 38-47. doi:

$10.1037 / \mathrm{a} 0017530$

Armeli, S., Dehart, T., Tennen, H., Todd, M., \& Affleck, G. (2007). Daily interpersonal stress and the stressor-vulnerability model of alcohol use. Journal of Social and Clinical Psychology, 26, 896-921. doi: 10.1521/jscp.2007.26.8.896

Armeli, S., Todd, M., \& Mohr, C. (2005). A daily process approach to individual differences in stress-related alcohol use. Journal of Personality, 73, 1657-1686. doi: 10.1111/j.0022-3506.2005.00362.x

Baker, T. B., Piper, M .E., McCarthy, D. E., Majeskie, M. R., \& Fiore, M. C. (2004). Addiction motivation reformulated: An affective processing model of negative reinforcement. Psychological Review, 111, 33-51. doi: 10.1037/0033295X.111.1.33

Beauchaine, T. (2001). Vagal tone, development, and Gray's motivational theory: Toward an integrated model of autonomic nervous system functioning in psychopathology. Development and Psychopathology, 13, 183-214. doi: 10.1017/S0954579401002012 
Boucsein, W. (2012) Electrodermal activity (2nd Ed). New York: Springer.

Boucsein, W., Fowles, D. C., Grimnes, S., Ben-Shakhar, G., Roth, W. T., Dawson, M. E., \& Filion, D. L. (2012). Publication recommendations for electrodermal measurements. Psychophysiology, 1017-1034. doi: 10.1111/j.14698986.2012.01384.x

Brown, T. A., Chorpita, B. F., Korotitsch, W, \& Barlow, D. H. (1997). Psychometric properties of the Depression Anxiety Stress Scales (DASS) in clinical samples. Behaviour Research and Therapy, 35, 79-89. doi: 10.1016/S00057967(96)00068-X

Buss, D. M. (1987). Selection, evocation, and manipulation. Journal of Personality and Social Psychology, 53, 1214-1221. doi: 10.1037/0022-3514.53.6.1214

Carnahan, R. M., Lund, B. C., Perry, P. J., Pollock, B. G., \& Culp, K. R. (2006). The anticholinergic drug scale as a measure of drug-related anticholinergic burden: Associations with serum anticholinergic activity. Journal of Clinical Pharmacology, 46, 1481-1486. doi: 10.1177/0091270006292126

Carpenter, J. S., Azzouz, F., Monahan, P. O., Storniolo, A. M., \& Ridner, S. H. (2005). Is sternal skin conductance monitoring a valid measure of hot flash intensity or distress? Menopause, 12, 512-519. doi: 10.1097/01.gme.0000170957.31542.1c

Carter, B. L, \& Tiffany, S. T. (1999). Meta-analysis of cue-reactivity in addiction research. Addiction, 94, 327-340. doi: 10.1046/j.1360-0443.1999.9433273.x

Chew, M. L., Mulsant, B. H., Pollock, B. G., Lehman, M. E., Greenspan, A., Mahmoud, R. A., .. . , Gharabawi, G. (2008). Anticholinergic activity of 107 medications 
commonly used by older adults. Journal of the American Geriatrics Society, 56, 1333-1341. doi: 10.1111/j.1532-5415.2008.01737.x

Conger, J. J. (1956). Reinforcement theory and the dynamics of alcoholism. Quarterly Journal of Studies on Alcohol, 17, 296-305.

Conrod, P. J., Peterson, J. B., \& Pihl, R. O. (2001). Reliability and validity of alcoholinduced heart rate increase as a measure of sensitivity to the stimulant properties of alcohol. Psychopharmacology, 157, 20-30. doi: 10.1007/s002130100741

Cooney, N. L., Litt, M. D., Cooney, J. L., Pilkey, D. T., Steinberg, H. R., \& Oncken, C. A. (2007). Alcohol and tobacco cessation in alcohol-dependent smokers: Analysis of real-time reports. Psychology of Addictive Behaviors, 21, 277-286. doi: 10.1037/0893-164X.21.3.277

Cooper, M.L., Frone, M.R., Russell, M. \& Mudar, P. (1995). Drinking to regulate positive and negative emotions: A motivational model of alcohol use. Journal of Personality and Social Psychology, 69, 990-1005. doi: 10.1037/00223514.69.5.990

Dawson, M. E., Schell, A. M., \& Filion, D. L. (2007). The Electrodermal System. In J. Cacioppo, L. G. Tassinary, \& G. G. Berntson (Eds.), Handbook of Psychophysiology (pp. 159-181). Cambridge: Cambridge University Press.

Donohue, K. F., Curtin, J. J., Patrick, C. J., \& Lang, A. R. (2007). Intoxication level and emotional response. Emotion, 7, 103-112. doi: 10.1037/1528-3542.7.1.103 
Elfering, A., \& Grebner, S. (2011). Ambulatory assessment of skin conductivity during first thesis presentation: Lower self-confidence predicts prolonged stress response. Applied Psychophysiology and Biofeedback, 36, 93-99. doi: 10.1007/s10484-011-9152-3

Fahrenberg, J. (1996). Ambulatory assessment: Issues and perspectives. In J. Fahrenberg \& M. Myrtek (Eds.). Ambulatory assessment: Computer assisted psychological and psychophysiological methods in monitoring and field studies (pp. 3-20). Seattle, WA: Hogrefe \& Huber.

Feldstein Ewing, S. W., Filbey, F. M., Chandler, L. D., \& Hutchison, K. E. (2010). Exploring the relationship between depressive and anxiety symptoms and neuronal response to alcohol cues. Alcoholism: Clinical and Experimental Research, 34, 396-403. doi: 10.1111/j.1530-0277.2009.01104.x

Finn, P. R., Earleywine, M., \& Pihl, R. O. (1992). Sensation seeking, stress reactivity, and alcohol dampening discriminate the density of a family history of alcoholism. Alcoholism: Clinical and Experimental Research, 16, 585-590. doi: 10.1111/j.1530-0277.1992.tb01421.x

First, M.G., Spitzer, R.L., Gibbon, M., \& Williams, J.B. (1995). Structured clinical interview for DSM-IV Axis I disorder—patient ed. (SCID-I/P, Version 2). New York: Biometrics Research Department, New York State Psychiatric Institute.

Foster, S.L., \& Cone, J.D. (1995). Validity issues in clinical assessment. Psychological Assessment, 7, 248-260. doi: 10.1037/1040-3590.7.3.248 
Fowles, D. C. (1980). The three arousal model: Implications of Gray's two-factor learning theory for heart rate, electrodermal activity, and psychopathy. Psychophysiology, 17, 87-104. doi: 10.1111/j.1469-8986.1980.tb00117.x

Gibbons, R. D., Hedeker, D., \& DuToit, S. (2010). Advances in analysis of longitudinal data. Annual Review of Clinical Psychology, 6, 79-107. doi:

10.1146/annurev.clinpsy.032408.153550

Gratz, K. L., \& Roemer, L. (2004). Multidimensional assessment of emotion regulation and dysregulation: Development, factor structure, and initial validation of the difficulties in emotion regulation scale. Journal of Psychopathology and Behavioral Assessment, 26, 41-54. doi: 10.1007/s10862-008-9102-4

Greeley, J., \& Oei, T. (1999). Alcohol and tension reduction. In K. E. Leonard \& H. T. Blane (Eds.). Psychological theories of drinking and alcoholism (pp. 14-53). New York: Guilford Press.

Gross, J. J., \& Levenson, R. W. (1995). Emotion elicitation using films. Cognition and Emotion, 9, 87-108. doi: 10.1080/02699939508408966

Hoehn-Saric, R., McLeod, D. R., Funderburk, F., \& Kowalski, P. (2004). Somatic symptoms and physiologic responses in generalized anxiety disorder and panic disorder: An ambulatory monitor study. Archives of General Psychiatry, 61, 913921. doi: 10.1001/archpsyc.61.9.913.

Hussong, A. M. (2007). Predictors of drinking immediacy following daily sadness: An application of survival analysis to experience sampling data. Addictive Behaviors, 32, 1054-1065. doi: 10.1016/j.addbeh.2006.07.011 
Hussong, A. M., Hicks, R. E., Levy, S. A., \& Curran, P. J. (2001). Specifying the relations between affect and heavy alcohol use among young adults. Journal of Abnormal Psychology, 110, 449-461. doi: 10.1037/0021-843X.110.3.449

Hustad, J. T. P., \& Carey, K. B. (2005). Using calculations to estimate blood alcohol concentrations for naturally occurring drinking episodes: A validity study. Journal of Studies on Alcohol and Drugs, 66, 130-138. doi: 10.15288/jsa.2005.66.130

Jones, B., Parsons, O., \& Rundell, O. (1976). Psychophysiological correlates of alcoholism. In R. E. Tarter \& A. Sugarman (Eds.), Alcoholism: Interdisciplinary approaches to an enduring problem (pp. 435-477). Reading, MA: AddisonWesley.

Kaplan, R. M., \& Stone, A. A. (2013). Bringing the laboratory and clinic to the community: Mobile technologies for health promotion and disease prevention. Annual Review of Psychology, 64, 471-498. doi: 10.1146/annurev-psych-113011143736

Kessler, R. C., Crum, R. M., Warner, L. A., Nelson, C. B., Schulenberg, J., \& Anthony, J. C. (1997). Lifetime co-occurrence of DSM-III-R alcohol abuse and dependence with other psychiatric disorders in the National Comorbidity Survey. Archives of General Psychiatry, 54, 313-321.

Koenigsberg, H. W. (2010). Affective instability: Toward an integration of neuroscience and psychological perspectives. Journal of Personality Disorders, 24, 60-82. doi: 10.1521/pedi.2010.24.1.60 
Koob, G.F., and Le Moal, M. (2001). Drug addiction, dysregulation of reward, and allostasis. Neuropsychopharmacology, 24, 97-129. doi: 10.1016/S0893$133 \mathrm{X}(00) 00195-0$

Kupka, R. W., Luckenbaugh, D. A., Post, R. M., Suppes, T., Altshuler, L. L., Keck, P. E., ..., Nolen, W. A. (2005). Comparison of rapid-cycling and non-rapid-cycling bipolar disorder based on prospective mood ratings in 539 outpatients. American Journal of Psychiatry, 162, 1273-1280. doi: 10.1176/appi.ajp.162.7.1273

Lecrubier, Y., Sheehan, D. V., Weiller, E., Amorim, P., Bonora, I., Sheehan, K. H., ... \& Dunbar, G. C. (1997). The Mini International Neuropsychiatric Interview (MINI). A short diagnostic structured interview: reliability and validity according to the CIDI. European Psychiatry, 12, 224-231.

Littell, R.C., Milliken, G.A., Stroup, W.W., and Wolfinger, R.D. (1996). SAS System for Mixed Models. Cary, NC: SAS Institute.

Lovibond, S.H., \& Lovibond, P.F. (1995). Manual for the Depression Anxiety Stress Scales. (2nd. Ed.) Sydney: Psychology Foundation.

Lykken, D. T., \& Venables, P. H. (1971). Direct measurement of skin conductance: A proposal for standardization. Psychophysiology, 8, 656-672. doi: 10.1111/j.14698986.1971.tb00501.x

Matthews, D. B., \& Miller, W. R. (1979). Estimating blood alcohol concentration: Two computer programs and their applications in therapy and research. Addictive Behaviors, 4, 55-60. doi: 10.1016/0306-4603(79)90021-2 
Meuret, A. E., Rosenfield, D., Wilhelm, F. H., Zhou, E., Conrad, A., Ritz, T., \& Roth, W. T. (2011). Do unexpected panic attacks occur spontaneously? Biological Psychiatry, 70, 985-991. doi: 10.1016/j.biopsych.2011.05.027

Mohr, C. D., Armeli, S., Tennen, H., Carney, M. A., Affleck, G., \& Hromi, A. (2001). Daily interpersonal experiences, context, and alcohol consumption: Crying in your beer and toasting good times. Journal of Personality and Social Psychology, 80, 489-500. doi: 10.1037/0022-3514.80.3.489

Morey, L. C. (1991). Personality Assessment Inventory: Professional manual. Odessa, FL: Psychological Assessment Resources.

Nezlek, J. B. (2012). Multilevel modeling analyses of diary-style data. In M. R. Mehl \& T. S. Conner (Eds.), Handbook of research methods for studying daily life (pp. 357-383). New York: Guilford Press.

Nocua, R., Noury, N., Gehin, C., Dittmar, A., \& McAdams, E. (2009, September). Evaluation of the autonomic nervous system for fall detection. In Engineering in Medicine and Biology Society, 2009. EMBC 2009. Annual International Conference of the IEEE (pp. 3225-3228). IEEE. doi: 10.1109/IEMBS.2009.5333165

Noel, N., Lisman, S. A., Schare, M., \& Lederer, J. (1981, April). Effects of alcohol before or after unsolvable puzzles: Prevention or alleviation of stress reactions. Presented at the meeting of the Eastern Psychological Association, New York. Orne, M. (1962). On the social psychology of the psychological experiment. American Psychologist, 17, 776-783. doi: 10.1037/h0043424 
Pachman, D. R., Loprinzi, C. L., Novotny, P. J., Satele, D. V., Linquist, B. M., Wolf, S., \& Barton, D. L. (2013). Sternal Skin Conductance: A reasonable surrogate for hot flash measurement? Menopause, 20, 1164-1168.

doi:10.1097/GME.0b013e31828cec53

Pfohl, B., Blum, N., \& Zimmerman, M. (1994). Structured interview for DSM-IV personality disorders. Iowa City: University of Iowa Hospitals and Clinics.

Picard, R. W., Fedor, S., \& Ayzenberg, Y. (in press). Multiple arousal theory and dailylife electrodermal activity asymmetry. Emotion Review. doi: $10.1177 / 1754073914565517$

Pietrzak, R. H., Goldstein, R. B., Southwick, S. M., \& Grant, B. F. (2011). Prevalence and axis I comorbidity of full and partial posttraumatic stress disorder in the United States: Results from wave 2 of the National Epidemiologic Survey on Alcohol and Related Conditions. Journal of Anxiety Disorders, 25, 456-465. doi: 10.1016/j.janxdis.2010.11.010

Poh, M. Z., Loddenkemper, T., Reinsberger, C., Swenson, N. C., Goyal, S., Sabtala, M. C., ... \& Picard, R. W. (2012). Convulsive seizure detection using a wrist-worn electrodermal activity and accelerometry biosensor. Epilepsia, 53, e93-e97. doi: 10.1111/j.1528-1167.2012.03444.x/full

Poh, M., Swenson, N. C., \& Picard, R. W. (2010). A wearable sensor for unobtrusive, long-term assessment of electrodermal activity. IEEE Transactions on Biomedical Engineering, 57, 1243-1252. doi: 10.1109/TBME.2009.2038487 
Rajan, S., Leonard, N., Fletcher, R., Casarjian, B., Casarjian, R., Cisse, C., \& Gwadz, M. (2012). Ambulatory autonomic activity monitoring among at-risk adolescent mothers. Journal of Mobile Technology in Medicine, 1, 25-31. doi: 10.7309/jmtm.19

Rottenberg, J., Ray, R. D., \& Gross, J. J. (2007). Emotion elicitation using films, In J. A. Coan \& J. J. B. Allen (Eds.), The handbook of emotion elicitation and assessment (pp. 9-28). London: Oxford University Press.

Rubenking, B., \& Lang, A. (2014). Captivated and grossed out: An examination of processing core and sociomoral disgusts in entertainment media. Journal of Communication, 64, 543-565. doi: 10.1111/jcom.12094

Sayette, M. A. (1993a). An appraisal-disruption model of alcohol's effects on stress responses in social drinkers. Psychological Bulletin, 114, 459-476. doi: 10.1037/0033-2909.114.3.459

Sayette, M. A. (1993b). Heart rate as an index of stress response in alcohol administration research: A critical review. Alcoholism: Clinical and Experimental Research, 17, 802-809. doi: 10.1111/j.1530-0277.1993.tb00845.x

Sayette, M. A., Martin, C. S., Perrott, M. A., Wertz, J. M., \& Hufford, M. R. (2001). A test of the appraisal-disruption model of alcohol and stress. Journal of Studies on Alcohol, 62, 247-256. doi: 10.15288/jsa.2001.62.247

Schlenker, R., Cohen, R., Hubmann, W., Mohr, F., Wahlheim, C., Watzl, H, \& Werther, P. (1995). Electrodermal and vascular orienting response in schizophrenic 
patients: Relationship to symptoms and medication. European Archives of Psychiatry and Clinical Neuroscience, 245, 152-158. doi: 10.1007/BF02193088

Sher, K. J. (1987). Stress response dampening. In H. T. Blane \& K. E. Leonard (Eds.), Psychological theories of drinking and alcoholism (pp. 227-271). New York: Guilford Press.

Sher, K. J. (1991). Children of alcoholics: A critical appraisal of theory and research. Chicago: University of Chicago Press.

Sher, K. J., Bartholow, B. D., Peuser, K., Erickson, D. J., \& Wood, M. D. (2007). Stressresponse dampening effects of alcohol: Attention as a mediator and moderator. Journal of Abnormal Psychology, 116, 362-377. doi: 10.1037/0021843X.116.2.362

Sher, K. J., \& Grekin, E. R. (2007). Alcohol and affect regulation. In J. Gross (Ed.), Handbook of emotion regulation (pp. 560-580). New York: Guilford.

Simpson, A., \& Turpin, G. (1983). A device for ambulatory skin conductance monitoring. Psychophysiology, 20, 225-229. doi: 10.1111/j.14698986.1983.tb03293.x

Snijders, T. A. B. \& R. J. Bosker (1999). Multilevel analysis: An introduction to basic and advanced multilevel modeling. Thousand Oaks, CA: Sage Publications.

Spybrook, J., Bloom, H., Congdon, R., Hill, C., Martinez, A., \& Raudenbush, S. (2011). Optimal Design for Longitudinal and Multilevel Research: Documentation for the Optimal Design Software Version 3.0. Available from www.wtgrantfoundation.org or from sitemaker.umich.edu/group-based. 
Swendsen, J. D., Tennen, H., Carney, M. A., Affleck, G., Willard, A., \& Hromi, A. (2000). Mood and alcohol consumption: An experience sampling test of the selfmedication hypothesis. Journal of Abnormal Psychology, 109, 198-204. doi: 10.1037//0021-843X. 109.2.198

Taylor, J. (2004). Electrodermal reactivity and its association to substance use disorders. Psychophysiology, 41, 982-989. doi: 10.1111/j.1469-8986.2004.00236.x

Todd, M., Armeli, S., \& Tennen, H. (2009). Interpersonal problems and negative mood as predictors of within-day time to drinking. Psychology of Addictive Behaviors, 23, 205-215. doi: 10.1037/a0014792

Todd, M., Armeli, S., Tennen, H., Carney, M.A., \& Affleck, G. (2003). A daily diary validity test of drinking to cope measures. Psychology of Addictive Behaviors, 17, 303-311. doi: 10.1037/0893-164X.17.4.303

Tomko, R. L., Trull, T. J., Wood, P. K., \& Sher, K. J. (2014). Characteristics of borderline personality disorder in a community sample: Comorbidity, treatment utilization, and general functioning. Journal of Personality Disorders, 28, 734 750. doi: 10.1521/pedi_2012_26_093

Treloar, H., Piasecki, T. M., McCarthy, D. M., Sher, K. J., \& Heath, A. C. (in press). Ecological evidence that affect and perceptions of drink effects depend on alcohol expectancies. Addiction. doi: 10.1111/add.12982

Turpin, G., Shine, P., \& Lader, M. (1983). Ambulatory electrodermal monitoring: Effects of ambient temperature, general activity, electrolyte media and length of 
recording. Psychophysiology, 20, 219-224. doi: 10.1111/j.1469-

8986.1983.tb03291.x

Udo, T., Bates, M. E., Mun, E. Y., Vaschillo, E. G., Vaschillo, B., Lehrer, P., \& Ray, S. (2009). Gender differences in acute alcohol effects on self-regulation of arousal in response to emotional and alcohol-related picture cues. Psychology of Addictive Behaviors, 23, 196-204. doi: 10.1037/a0015015

van Dooren, M., de Vries, J.J.G., \& Janssen, J. H. (2012). Emotional sweating across the body: Comparing 16 different skin conductance measurement locations. Physiology and Behavior, 106, 298-304. doi:10.1016/j.physbeh.2012.01.020

Volpicelli, J. R. (1987). Uncontrollable events and alcohol drinking. British Journal of Addiction, 82, 381-392. doi: 10.1111/j.1360-0443.1987.tb01494.x

Watson, D., \& Clark, L. A. (1999). The PANAS-X: Manual for the Positive and Negative Affect Schedule-Expanded Form. Unpublished manuscript, University of Iowa, Iowa City, IA.

Watson, D., Clark, L. A., \& Tellegen, A. (1988). Development and validation of brief measures of Positive and Negative Affect: The PANAS scales. Journal of Personality and Social Psychology, 54, 1063-1070. doi: 10.1037/00223514.54.6.1063

Weise, S., Ong, J., Tesler, N. A., Kim, S., \& Roth, W. T. (2013). Worried sleep: 24-h monitoring in high and low worriers. Biological Psychology, 94, 61-70. doi: 10.1016/j.biopsycho.2013.04.009

Wikler, A. (1948). Recent progress in research on the neurophysiologic basis of morphine addiction. American Journal of Psychiatry, 105, 329-338. 
Wilhelm, F. H., \& Roth, W. T. (1998). Taking the laboratory to the skies: Ambulatory assessment of self-report, autonomic, and respiratory responses in flying phobia. Psychophysiology, 35, 596-606. doi: 10.1017/S0048577298970196 


\section{VITA}

Rachel Lynn Tomko was born in Pittsburgh, Pennsylvania. After graduating from Thomas Jefferson High School in Jefferson Hills, Pennsylvania, she completed a Bachelor of Science degree in Psychology from Pennsylvania State University in 2008. She received her Master of Arts degree in Clinical Psychology from the University of Missouri in 2011 and completed her Clinical Psychology pre-doctoral internship at the Medical University of South Carolina in 2015. She will receive her Ph.D. in Clinical Psychology from the University of Missouri in August 2015. After completion of her Ph.D., she will continue her training at the Medical University of South Carolina as a postdoctoral fellow, with a focus on substance use research. 